\title{
How the Quantitative Easing Affect the Spillover Effects between the Metal Market and United States Dollar Index?
}

\author{
Jung-Bin Su*
}

\author{
Department of Finance, China University of Science and Technology, No.245, Sec. 3, Academia Rd., \\ Nangang Dist., Taipei 11581, Taiwan, R.O.C.
}

\begin{abstract}
This study explores both return and volatility spillover effects, the co-integration relation and the correlative relationship between the metal market in London metal exchange and United States exchange rate market, and the risk premium and leverage effect in each of these two markets for the periods before and during quantitative easing (QE). Empirical results show that, as the QE is executed the risk premium in US exchange rate market will disappear; and the speed and direction of the adjustment back to equilibrium respectively becomes greater and is reversed for the cointegration relation in metal market. Regarding these two markets only the return spillover effect is affected, and the degree of negative correlative relationship becomes more obvious as the QE is executed.
\end{abstract}

Keywords: Spillover effect, United States dollar index, Metal market, Quantitative easing.

\section{INTRODUCTION}

The global financial crisis ran from January 2, 2007 to December 31,2008 . This crisis was regarded as the worst since the Great Depression of the 1930s because it brought about the threat of total collapse in large financial institutions, the bailout of banks by national governments, and the downturns in stock markets around the world. Moreover, the housing market also suffered in many areas, resulting in evictions, foreclosures on residences, and prolonged unemployment. Therefore this crisis played a significant role in the failure of key businesses, the decline in consumer wealth, and a downturn in economic activity. It further led to a global recession between 2008 and 2012 and contributed to the European sovereign debt crisis. As a consequence of the financial crisis, the United States (US) has implemented a policy of quantitative easing (QE) ${ }^{1}$ since November 2008 to deal with the bad financial situation and stimulate an economic recovery. This policy may force the depreciation of the United States dollar (USD). Moreover, the USD is an international currency since a number of commodities, such as crude oil in the energy market; gold $(\mathrm{Au})$, aluminum (Al), copper

*Address correspondence to this author at the Department of Finance, China University of Science and Technology, No.245, Sec. 3, Academia Rd., Nangang Dist., Taipei 11581, Taiwan, R.O.C.; Tel: +886 227864501 ext 16; Fax: +886 2 27864574; E-mail: jungbinsu@cc.cust.edu.tw,

jungbinsu@gmail.com

\footnotetext{
${ }^{1}$ Quantitative easing (QE) is an unconventional monetary policy used by central banks to stimulate the national economy when standard monetary policy has become ineffective. A central bank implements the quantitative easing by buying financial assets from commercial banks and other private institutions, thus creating money and injecting a pre-determined amount of money into the economy. Moreover, before the QE policy executed by US, the Bank of Japan (BOJ)'s monetary policy, a similar QE policy, was performed by Japan in 2006.
}

$(\mathrm{Cu})$, lead $(\mathrm{Pb})$, nickel $(\mathrm{Ni})$, tin $(\mathrm{Sn})$, and zinc $(\mathrm{Zn})$ in the metal market of the London metal exchange (LME); and cocoa, corn, wheat, and soybean meal in the agricultural commodity market are valued in USD. Furthermore, internationalization is widespread in most countries all over the world thus capital may flow from one country to another country, from one market to another market, and from one asset to another asset. That is, I may predict the trend of price level for one type of commodity from that for another type of commodity if the direction of capital flow is given. These facts give rise to several questions, such as whether the depreciating USD will lead to the increasing price levels of metal raw materials and vice versa, whether a spillover effect on return and volatility exists between the metal market in LME and the US exchange rate market, whether the co-integration relation, leverage effect and volatility feedback effect subsist in these two markets and, with regard to the topics mentioned above, what is the difference between the pre-QE and QE periods? These questions can be answered by the leverage effect and risk premium in each of two markets; and the return and volatility spillover effects, and the conditioned correlation between these two markets for the pre-QE and QE periods.

Subsequently, I will review the relevant research published in the past. First, with regard to the topic of $\mathrm{QE}$, most of the literature has focused on the effects of QE via examining the variation of macroeconomic variables such as the inflation, industrial production, gross domestic product and the consumer price index (see Karras 2013; Lyonnet and Werner 2012; Schenkelberg and Watzka 2013 and so on) or by inspecting the changes in financial variables such as 
the bank equity value, exchange rates, and interest rates (see Nakazono and Ueda 2013; Schenkelberg and Watzka 2013). Second, in regard to the issue of the correlative relationship between two types of markets or commodities, the types of markets or commodities that are used to explore the return and volatility spillover effects can be classified into the following cases. Past literature has focused on the return and volatility spillover effects between several stock markets (see Allen, Amrama, and McAleer 2013; Lee 2013; Singh, Kumar, and Pandey 2010 and so on); between several exchange rate markets (see Antonakakis 2012; Kitamura 2010; McMillan and Speight 2010 and so on); between several bond markets (see Skintzi and Refenes 2006); between the stock market and exchange rate market (see Zhao 2010); between the stock market and bond market (see Dean, Faff, and Loudon 2010); between the money market and interest rate market (see Zaghini and Colarossi 2009) and between the stock market and commodity market (see Mensi, Beljid, Boubaker, and Managi 2013).

The literature mentioned above does not touch on the issue of the correlative relationship between the US exchange rate market and the metal market. That is, they do not explore the topic of the relationship between the depreciating USD and the increasing price level of metal raw materials, and vice versa, in the years since the policy of $Q E$ has been taken up by United States. Hence, with regard to the pre-QE and $\mathrm{QE}$ periods, this study employs two bivariate asymmetric BEKK ${ }^{2}$-GARCH models which assure the property of a positive definite to estimate the conditional variance and covariance of seven pairs of data composed of the commodities in the metal market of LME and the United States dollar index (UDI), representing the US exchange rate market, as AI-UDI, Au-UDI, Cu-UDI, Ni-UDI, Pb-UDI, Sn-UDI, and $\mathrm{Zn-}$ UDI, and to explore both return and volatility spillover effects, the correlative relationship between these two markets, and the risk premium and leverage effect in each of these two markets, and further explore how the above financial phenomena be changed as the QE is executed. Our results show that, as the QE is executed some financial phenomena are changed significantly. For example, the return spillover effect from US exchange rates market to metal market in LME since the negative return spillover effect disappears, and

${ }^{2}$ The BEKK type of model is named after Baba, Engle, Kraft, and Kroner (1990). from metal market to US exchange rates market since the negative return spillover is changed into positive one; the co-integration relation in metal market since the speed of adjustment back to equilibrium becomes greater and the direction of this adjustment is reversed; the risk premium in US exchange rates market since the volatility feedback effect disappears; and the correlative relation between these two markets since the degree of negative correlative relationship becomes more obvious. As to the remainder financial phenomena, they are similar for the periods of pre-QE and QE.

The remainder of this paper is organized as follows. Section 2 describes the empirical models utilized in this study -two asymmetric type of bivariate $\mathrm{GARCH}$ models. Section 3 states the basic statistical features for the return series of UDI and seven metal commodities in LME. Section 4 analyzes the empirical results and further explores the issues addressed in this work. Finally, the conclusion is drawn in the last section.

\section{ECONOMETRIC METHODOLOGY}

In this study, several bivariate GARCH models are used to explore the spillover effects and other financial phenomena between the metals market in LME and US exchange rate market. These models are composed of mean equation and variance-covariance equation. If the two series are bound by some relationship in the long run then the vector autoregressive (VAR) framework needs to be modified to allow consistent estimation of the relationships between them. Thus the mean equation of these models is expressed as the form of the vector error correction model (VECM) with lag $2^{3}$ model since VECM can take into account any cointegrating relationships between them. Moreover, the bivariate variance-covariance specification derived in the Appendix of Su $(2014)^{4}$ is utilized estimate the conditional variance and covariance of seven pairs of data, and further to explore several financial issues mentioned above. This bivariate variance-covariance specification owns the property of not only positive definite in the covariance matrix but also parsimony in the parameter estimation. Subsequently, based on the

\footnotetext{
${ }^{3}$ Since the maximum value (in absolute value) of Schwarz's Bayesian Criterion (SBC) occurs at the lag 2 for all seven pairs of data, hence the optimal lag number should be two based on SBC. Please see section of empirical results for more details.

${ }^{4}$ Su (2014) adopted Moschini and Myers's (2002) suggestion to simplify the BEKK model, and derived a positive definite type of bivariate asymmetric GARCH model in diagonal representation, B-GJR-GARCH model.
} 
variance-covariance specifications described above, two asymmetric types ${ }^{5}$ of bivariate GARCH models are represented as follows.

The positive definite type of bivariate $\operatorname{VECM}(2)$ BEKK-GJR-GARCH $(1,1)-\mathrm{MX}$ model (hereafter, B-GJRGARCH) is utilized to explore the spillover effects between the metal commodities in LME and the United States dollar index (UDI). The VECM(2) type of return specification is used to investigate the return spillover effect between these two markets, and the risk premium and co-integration relation in each of two markets, and is represented as $R_{t}=\left[R_{1, t}, R_{2, t}\right]^{\prime}$. On the contrary, the BEKK-GJR-GARCH(1,1)-MX type of variance-covariance specification model is employed to investigate the volatility spillover effect and the correlative relation between these two markets, and the leverage effect in each of two markets. This type of variance-covariance specification takes the form of one asset's variance being expressed as the form of GJR-GARCH $(1,1)$ and involves the variance of another asset as the exogenous variable. Additionally, two time dummies $\left(\mathrm{D}_{\mathrm{t}}^{\mathrm{BQE}}\right.$ and $\left.\mathrm{D}_{\mathrm{t}}^{\mathrm{QE}}\right)$ are set on part of the parameters in order to consider the issues explored in this study for two sub-periods, pre-QE and QE.

$$
\begin{aligned}
& \mathrm{R}_{1, \mathrm{t}}=\varphi_{10}+\sum_{\mathrm{i}=1}^{2} \varphi_{11 \mathrm{i}} \mathrm{R}_{1, t-\mathrm{i}}+\sum_{\mathrm{i}=1}^{2} \varphi_{12 \mathrm{i}} \mathrm{R}_{2, \mathrm{t}-\mathrm{i}}+\sum_{\mathrm{i}=1}^{2} \varphi_{13 \mathrm{i}} \mathrm{R}_{12, \mathrm{t}-\mathrm{i}}+\delta_{1} \ln \left(\mathrm{h}_{11, \mathrm{t}}\right)+\varepsilon_{1, \mathrm{t}} \\
& \mathrm{R}_{2, \mathrm{t}}=\varphi_{20}+\sum_{\mathrm{i}=1}^{2} \varphi_{21 \mathrm{i}} \mathrm{R}_{1, t-\mathrm{i}}+\sum_{\mathrm{i}=1}^{2} \varphi_{22 \mathrm{i}} \mathrm{R}_{2, \mathrm{t}-\mathrm{i}}+\sum_{\mathrm{i}=1}^{2} \varphi_{23 \mathrm{i}} \mathrm{R}_{12, \mathrm{ti}}+\delta_{2} \ln \left(\mathrm{h}_{22, \mathrm{t}}\right)+\varepsilon_{2, \mathrm{t}}
\end{aligned}
$$

$\varepsilon_{\mathrm{t}} \mid \Omega_{\mathrm{t}-1} \sim \mathrm{N}\left(0, \mathrm{H}_{\mathrm{t}}\right)$

$\mathrm{h}_{\mathrm{t}}=\operatorname{vech}\left(\mathrm{H}_{\mathrm{t}}\right)=\left[\mathrm{h}_{11, \mathrm{t}}, \mathrm{h}_{12, \mathrm{t}}, \mathrm{h}_{22, \mathrm{t}}\right]$

$\mathrm{h}_{11, \mathrm{t}}=\omega_{1}+\left(\alpha_{1}+\eta_{1} \mathrm{D}_{1, \mathrm{t}-1}^{-}\right) \varepsilon_{1, \mathrm{t}-1}^{2}+\beta_{1} \mathrm{~h}_{11, \mathrm{t}-1}+v_{1} \mathrm{~h}_{22, \mathrm{t}-1}$

$\mathrm{h}_{12, \mathrm{t}}=\omega_{12}+\alpha_{12} \varepsilon_{1, \mathrm{t}-1} \varepsilon_{2, \mathrm{t}-1}+\beta_{12} \mathrm{~h}_{12, \mathrm{t}-1}$

$\mathrm{h}_{22, \mathrm{t}}=\omega_{2}+\left(\alpha_{2}+\eta_{2} \mathrm{D}_{2, \mathrm{t}-1}^{-}\right) \varepsilon_{2, \mathrm{t}-1}^{2}+\beta_{2} \mathrm{~h}_{22, \mathrm{t}-1}+v_{2} \mathrm{~h}_{11, \mathrm{t}-1}$

where

$$
\mathrm{R}_{\mathrm{j}, \mathrm{t}}=\left(\ln \mathrm{P}_{\mathrm{j}, \mathrm{t}}-\ln \mathrm{P}_{\mathrm{j}, \mathrm{t}-1}\right) \times 100
$$

and

$D_{j, t-1}^{-}=\left\{\begin{array}{ll}1 & \text { if } \quad \varepsilon_{j, t-1}<0 \\ 0 & \text { otherwise }\end{array}\right.$ for $j=1,2 . \quad R_{1, t} \quad$ and $R_{2, t}$ represent the return of the commodities in the metal market of LME and UDI in the US exchange rate

\footnotetext{
${ }^{5}$ According to the past literature - see Fama (1965), Mandelbrot (1963), Su (2015) and so on - most financial asset returns series possess features of volatility such as volatility pooling and leverage effects. To capture the stylized facts of financial asset returns described above, this study utilizes two asymmetric types of GARCH model - the threshold GARCH (GJR-GARCH) model proposed by Glosten, Jagannathan, and Runkle (1993) and exponential GARCH (EGARCH) of Nelson (1991) - to explore the volatility spillover effect between the metal commodities in LME and the UDI.
}

market, respectively. $\quad \mathrm{R}_{12, \mathrm{t}}=\left(\ln \mathrm{P}_{2, \mathrm{t}}-\ln \mathrm{P}_{1, \mathrm{t}}\right) \times 100$ denotes the error correction term. Parameters $\varphi_{13 \mathrm{i}}$ and $\varphi_{23 \mathrm{i}}$ describe the speed of adjustment back to equilibrium, and they can measure the proportion of last period's equilibrium error that is corrected for. The conditional distribution of $\varepsilon_{\mathrm{t}}=\left[\varepsilon_{1, t}, \varepsilon_{2, \mathrm{t}}\right]^{\prime}$ is assumed to follow the normal distribution with $\mathrm{E}_{\mathrm{t}-1}\left(\varepsilon_{\mathrm{t}}\right)=0, \mathrm{E}_{\mathrm{t}-1}\left(\varepsilon_{\mathrm{t}} \varepsilon_{\mathrm{t}}^{\prime}\right)=\mathrm{H}_{\mathrm{t}}$. In this variance specification, the term $\left(\alpha_{\mathrm{j}}+\eta_{\mathrm{j}} \mathrm{D}_{\mathrm{j}, \mathrm{t}-1}^{-}\right)$equals $\alpha_{\mathrm{j}}+\eta_{\mathrm{j}}$ as $\varepsilon_{\mathrm{j}, \mathrm{t}-1}<0$ or equals $\alpha_{\mathrm{j}}$ for $\varepsilon_{\mathrm{j}, \mathrm{t}-1}>0$ for $\mathrm{j}=1,2$. Hence, if parameter $\eta_{j}$ is significantly positive then a leverage effect of volatility exists owing to higher volatility being obtained by bad news than by good news, implying that parameter $\eta_{\mathrm{j}}$ can be used to capture the leverage effect of volatility.

Regarding the QE effect, parameters $\varphi_{12 \mathrm{i}}, \varphi_{21 \mathrm{i}}$, $\varphi_{13 \mathrm{i}}, \varphi_{23 \mathrm{i}}, \delta_{1}, \delta_{2}, v_{1}, v_{2}, \eta_{1}, \eta_{2}$ and $\omega_{12}$ are defined as follows.

$$
\begin{aligned}
& \varphi_{12 \mathrm{i}}=\varphi_{12 \mathrm{i}}^{\mathrm{BQE}} \cdot \mathrm{D}_{\mathrm{t}}^{\mathrm{BQE}}+\varphi_{12 \mathrm{i}}^{\mathrm{QE}} \cdot \mathrm{D}_{\mathrm{t}}^{\mathrm{QE}}, \varphi_{21 \mathrm{i}}=\varphi_{21 \mathrm{i}}^{\mathrm{BQE}} \cdot \mathrm{D}_{\mathrm{t}}^{\mathrm{BQE}}+\varphi_{21 \mathrm{i}}^{\mathrm{QE}} \cdot \mathrm{D}_{\mathrm{t}}^{\mathrm{QE}}, \\
& \varphi_{13 \mathrm{i}}=\varphi_{13 \mathrm{i}}^{\mathrm{BQE}} \cdot \mathrm{D}_{\mathrm{t}}^{\mathrm{BQE}}+\varphi_{13 \mathrm{i}}^{\mathrm{QE}} \cdot \mathrm{D}_{\mathrm{t}}^{\mathrm{QE}}, \varphi_{23 \mathrm{i}}=\varphi_{23 \mathrm{i}}^{\mathrm{BQE}} \cdot \mathrm{D}_{\mathrm{t}}^{\mathrm{BQE}}+\varphi_{23 \mathrm{i}}^{\mathrm{QE}} \cdot \mathrm{D}_{\mathrm{t}}^{\mathrm{QE}}, \\
& \delta_{1}=\delta_{1}^{\mathrm{BQE}} \cdot \mathrm{D}_{\mathrm{t}}^{\mathrm{BQE}}+\delta_{1}^{\mathrm{QE}} \cdot \mathrm{D}_{\mathrm{t}}^{\mathrm{QE}}, \quad \delta_{2}=\delta_{2}^{\mathrm{BQE}} \cdot \mathrm{D}_{\mathrm{t}}^{\mathrm{BQE}}+\delta_{2}^{\mathrm{QE}} \cdot \mathrm{D}_{\mathrm{t}}^{\mathrm{QE}}, \\
& v_{1}=v_{1}^{\mathrm{BQE}} \cdot \mathrm{D}_{\mathrm{t}}^{\mathrm{BQE}}+v_{1}^{\mathrm{QE}} \cdot \mathrm{D}_{\mathrm{t}}^{\mathrm{QE}}, v_{2}=v_{2}^{\mathrm{BQE}} \cdot \mathrm{D}_{\mathrm{t}}^{\mathrm{BQE}}+v_{2}^{\mathrm{QE}} \cdot \mathrm{D}_{\mathrm{t}}^{\mathrm{QE}} \text {, } \\
& \eta_{1}=\eta_{1}^{\mathrm{BQE}} \cdot \mathrm{D}_{\mathrm{t}}^{\mathrm{BQE}}+\eta_{1}^{\mathrm{QE}} \cdot \mathrm{D}_{\mathrm{t}}^{\mathrm{QE}}, \eta_{2}=\delta_{2}^{\mathrm{BQE}} \cdot \mathrm{D}_{\mathrm{t}}^{\mathrm{BQE}}+\delta_{2}^{\mathrm{QE}} \cdot \mathrm{D}_{\mathrm{t}}^{\mathrm{QE}} \text {, } \\
& \omega_{12}=\omega_{12}^{\mathrm{BQE}} \cdot \mathrm{D}_{\mathrm{t}}^{\mathrm{BQE}}+\omega_{12}^{\mathrm{QE}} \cdot \mathrm{D}_{\mathrm{t}}^{\mathrm{QE}} \text {, } \\
& D_{t}^{B Q E}=\left\{\begin{array}{ll}
1 & \text { if } \text { date }_{\text {start }} \leq t<11 / 1 / 2008 \\
0 & \text { otherwise }
\end{array},\right. \\
& D_{t}^{Q E}= \begin{cases}1 & \text { if } t \geq 11 / 1 / 2008 \\
0 & \text { otherwise }\end{cases}
\end{aligned}
$$

$\mathrm{D}_{\mathrm{t}}^{\mathrm{BQE}}$ and $\mathrm{D}_{\mathrm{t}}^{\mathrm{QE}}$ are the time indicator dummies that take the value 1 if the time is before November 1, 2008 (i.e. the pre-QE period), and after November 1, $2008^{6}$ until the end date of the study sample (i.e. the period of

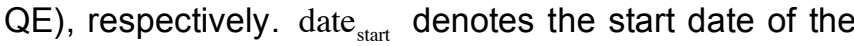
study sample. The parameters $\varphi_{12 \mathrm{i}}^{\mathrm{BQE}}$ and $\varphi_{12 \mathrm{i}}^{\mathrm{QE}}$ can respectively seize the return spillover effect from the US exchange rate market to the metal market for the pre-QE period and during the period of $Q E$. Conversely, parameters $\varphi_{21 \mathrm{i}}^{\mathrm{BQE}}$ and $\varphi_{21 \mathrm{i}}^{\mathrm{QE}}$ can respectively

\footnotetext{
${ }^{6}$ Quantitative easing was performed by United States after November 1, 2008 This time was just the end of the global financial crisis. Hence, the time period after the global financial crisis is that in which quantitative easing was implemented.
} 
capture the return spillover effect from the metal market to the US exchange rate market for the period pre-QE and during the period of QE. $\varphi_{13 \mathrm{i}}^{\mathrm{BQE}}$ and $\varphi_{23 \mathrm{i}}^{\mathrm{BQE}}$ can respectively describe the speed of adjustment back to equilibrium for the metal and US exchange rate markets during the pre-QE period whereas $\varphi_{13 \mathrm{i}}^{\mathrm{QE}}$ and $\varphi_{23 \mathrm{i}}^{\mathrm{QE}}$ can respectively describe the speed of adjustment back to equilibrium for the metal and US exchange rate markets during the period of QE. The parameters $\delta_{1}$ and $\delta_{2}$ in Eq. (1) are interpreted as the coefficients of relative risk aversion (Merton 1980), and they can be regarded as a time-varying risk premium. That is, the increased expected rate of return is required in response to an increase in the predictable variance of the return. Additionally, since the term $\ln \left(h_{i j, t}\right), j=1,2$ is included in the mean equation, parameters $\delta_{1}^{\mathrm{BQE}}$ and $\delta_{1}^{\mathrm{QE}}$ can respectively seize the volatility feedback effect in the metal market for the period pre-QE and during the period of $\mathrm{QE}$. Moreover, parameters $\delta_{2}^{\mathrm{BQE}}$ and $\delta_{2}^{\mathrm{QE}}$ can respectively seize the volatility feedback effect in the US exchange rate market for the period pre-QE and during the period of $\mathrm{QE}$.

The parameters $v_{1}^{\mathrm{BQE}}$ and $v_{1}^{\mathrm{QE}}$ are respectively utilized to seize the volatility spillover effect from the US exchange rate market to metal market for the pre$\mathrm{QE}$ and QE periods, whereas parameters $v_{2}^{\mathrm{BQE}}$ and $v_{2}^{\mathrm{QE}}$ are respectively utilized to capture the volatility spillover effect from the metal market to the US exchange rate market for the period pre-QE and during the QE period. Parameters $\eta_{1}^{\mathrm{BQE}}$ and $\eta_{1}^{\mathrm{QE}}$ can respectively seize the leverage effect in the metal market for the period pre-QE and during the period of QE. Moreover, the parameters $\eta_{2}^{\mathrm{BQE}}$ and $\eta_{2}^{\mathrm{QE}}$ can respectively seize the leverage effect in the US exchange rate market for the period pre-QE and during the period of QE. The parameters $\omega_{12}^{\mathrm{BQE}}$ and $\omega_{12}^{\mathrm{QE}}$ are employed to judge the correlative relationship in price trend between the metal market and the US exchange rate market for the period pre-QE and during the period of $\mathrm{QE}$, respectively. Furthermore, the parameters of this bivariate asymmetric GARCH model are estimated by maximum likelihood (ML) optimizing numerically the Gaussian log-likelihood function. Hence the loglikelihood function of the B-GJR-GARCH model $^{7}$ for the $Q E$ effect can be written as follows:

\footnotetext{
${ }^{7}$ The parameters in this model don't easily converge in case of using small data since 44 parameters are estimated in this model. In this case the small amount of data must be expanded to large amount of data via the bootstrap approach proposed by Efron (1979) to repeatedly resample the original small amount of data approach.
}

$$
\begin{aligned}
& \mathrm{L}(\psi)=\sum_{\mathrm{t}=1}^{\mathrm{T}} \ln \left\{\mathrm{f}\left(\mathrm{R}_{\mathrm{t}} \mid \Omega_{\mathrm{t}-1} ; \psi\right)\right\} \\
& =-\frac{\mathrm{T}}{2} \ln 2 \pi-\frac{1}{2} \sum_{\mathrm{t}=1}^{\mathrm{T}}\left(\ln \left|\mathrm{H}_{\mathrm{t}}\right|+\varepsilon_{\mathrm{t}}^{\prime} \mathrm{H}_{\mathrm{t}}^{-1} \varepsilon_{\mathrm{t}}\right)
\end{aligned}
$$

where $\psi=\left[\varphi_{10}, \varphi_{111}, \varphi_{112}, \varphi_{121}^{\mathrm{BQE}}, \varphi_{121}^{\mathrm{QE}}, \varphi_{122}^{\mathrm{BQE}}, \varphi_{122}^{\mathrm{QE}}, \varphi_{131}^{\mathrm{BQE}}, \varphi_{131}^{\mathrm{QE}}\right.$, $\varphi_{132}^{\mathrm{BQE}}, \varphi_{132}^{\mathrm{QE}}, \varphi_{20}, \varphi_{211}^{\mathrm{BQE}}, \varphi_{211}^{\mathrm{QE}}, \varphi_{212}^{\mathrm{BQE}}, \varphi_{212}^{\mathrm{QE}}, \varphi_{221}, \varphi_{222}, \varphi_{231}^{\mathrm{BQE}}, \varphi_{231}^{\mathrm{QE}}, \varphi_{232}^{\mathrm{BOE}}$, $\varphi_{232}^{\mathrm{QE}}, \delta_{1}^{\mathrm{BQE}}, \delta_{1}^{\mathrm{QE}}, \delta_{2}^{\mathrm{BQE}}, \delta_{2}^{\mathrm{QE}}, \omega_{1}, \alpha_{1}, \beta_{1}, \omega_{12}^{\mathrm{BQE}}, \omega_{12}^{\mathrm{QE}}, \alpha_{12}, \beta_{12}, \omega_{2}, \alpha_{2}$, $\left.\beta_{2}, v_{1}^{\mathrm{BQE}}, v_{1}^{\mathrm{QE}}, v_{2}^{\mathrm{BQE}}, v_{2}^{\mathrm{QE}}, \eta_{1}^{\mathrm{BQE}}, \eta_{1}^{\mathrm{QE}}, \eta_{2}^{\mathrm{BQE}}, \eta_{2}^{\mathrm{QE}}\right]$ is the vector of parameters to be estimated, $\mathrm{f}$ denotes the bivariate normal density and $\Omega_{t-1}$ denotes the information set of all observed returns up to time $\mathrm{t}-1$. In addition, the variance-covariance specification of the B-GJRGARCH-MX model is replaced by the EGARCH model, the B-EGARCH-MX model (hereafter, B-EGARCH) is acquired, and this variance-covariance specification is represented as below.

$$
\begin{aligned}
& \ln \left(\mathrm{h}_{11, \mathrm{t}}\right)=\omega_{1}+\beta_{1} \ln \left(\mathrm{h}_{11, t-1}\right)+\eta_{1} \frac{\varepsilon_{1, t-1}}{\sqrt{\mathrm{h}_{11, t-1}}}+\alpha_{1}\left[\frac{\left|\varepsilon_{1, t-1}\right|}{\sqrt{\mathrm{h}_{11, t-1}}}-\sqrt{\frac{2}{\pi}}\right]+v_{1} \ln \left(\mathrm{h}_{22, t-1}\right) \\
& \mathrm{h}_{12, \mathrm{t}}=\omega_{12}+\alpha_{12} \varepsilon_{1, t-1} \varepsilon_{2, t-1}+\beta_{12} \mathrm{~h}_{12, t-1} \\
& \ln \left(\mathrm{h}_{22, \mathrm{t}}\right)=\omega_{2}+\beta_{2} \ln \left(\mathrm{h}_{22, t-1}\right)+\eta_{2} \frac{\varepsilon_{2, t-1}}{\sqrt{\mathrm{h}_{22, t-1}}}+\alpha_{2}\left[\frac{\left|\varepsilon_{2, t-1}\right|}{\sqrt{\mathrm{h}_{22, t-1}}}-\sqrt{\frac{2}{\pi}}\right]+v_{2} \ln \left(\mathrm{h}_{11, t-1}\right)
\end{aligned}
$$

Notably, the model has two advantages over the pure GARCH specification. That is, first, even if the parameters are estimated as negative, $h_{\mathrm{j}, \mathrm{t}, \mathrm{j}} \mathrm{j}=1,2$ will be positive owing to the $\ln \left(\mathrm{h}_{\mathrm{j}, \mathrm{t}} \mathrm{t}\right)$ being modeled. Thus there is no need to artificially impose non-negativity constrains on the model parameters such as $\omega_{\mathrm{j}}, \alpha_{\mathrm{j}}$ and $\beta_{j}$ for $j=1,2$. Second, asymmetries are allowed for under the EGARCH formulation, since if the relationship between volatility and return is negative, the value of $\eta_{j}$, $\mathrm{j}=1,2$ will be negative. Hence, parameter $\eta_{\mathrm{j}}$ can be used to capture the leverage effect of volatility.

\section{DATA PRELIMINARY ANALYSIS}

In this study, both the return and volatility spillover effects between the metals market in LME and US exchange rate market are explored. Hence, the study data covers the $\mathrm{UDI}^{8}$ in the US exchange rate market and metal commodities on the LME, such as aluminum (Al; \$/ton), gold (Au; \$/ounce), copper (Cu; \$/ton), nickel (Ni; \$/ton), lead $(\mathrm{Pb} ; \$ /$ ton), tin (Sn; \$/ton), and zinc ( $\mathrm{Zn} ; \$ /$ ton). The first (second) word in the parentheses beside the name of the metal commodity

\footnotetext{
${ }^{8}$ The United States dollar index (UDI) in this study was a weighted geometric mean of the dollar's value compared only with a "basket" of 6 other major currencies. The major currencies include the euro, Japanese yen, Canadian dollar, British pound, Swedish krona and Swiss franc.
} 
Table 1: Descriptive Statistics of Daily Return for Overall Period, Pre-QE and QE Periods

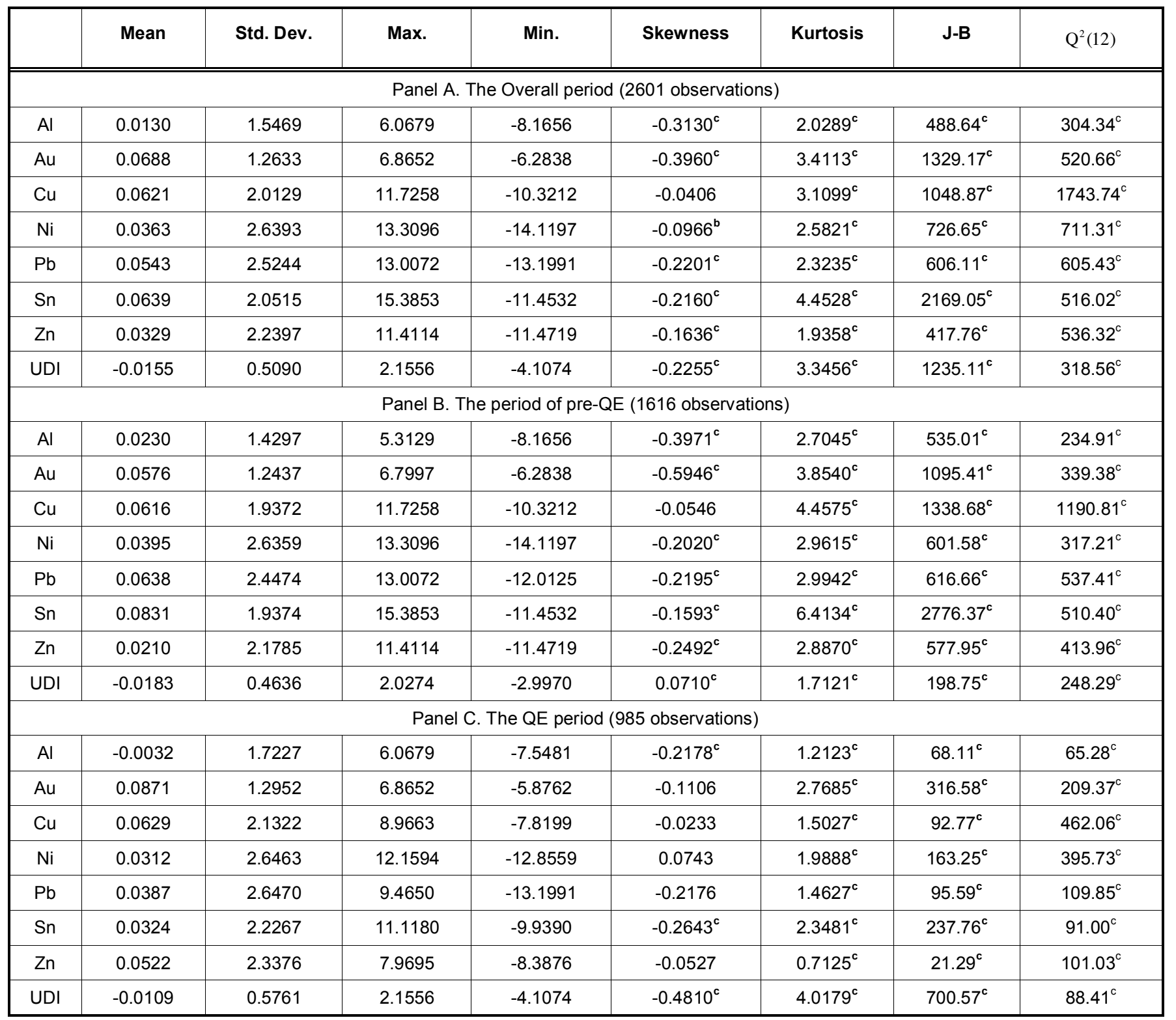

Note: 1. a, b and c denote significantly at the $10 \%, 5 \%$ and $1 \%$ levels, respectively. 2. Kurtosis denotes the excess kurtosis. 3 . J-B statistics are based on Jarque and Bera (1987) and are asymptotically chi-squared-distributed with 2 degrees of freedom. $4 . \mathrm{Q}^{2}(12)$ statistics are asymptotically chi-squared-distributed with 12 degrees of freedom.

denotes the corresponding expression of chemical element (the trade price per measurement unit). The daily close price data of these seven metal commodities and UDI were downloaded from Bloomberg. These seven pairs of data ${ }^{9}$ (Al-UDI, AuUDI, Cu-UDI, Ni-UDI, Pb-UDI, Sn-UDI, and Zn-UDI) start from January 14, 2002 and end on November 15, 2012, totaling 2,601 observations. Moreover, the

${ }^{9}$ For each pair of data, they are retained for the same trade date, and are deleted otherwise. Taking as an example the Au-UDI pair of data: both Au and UDI are traded on January 31,2002 , thus the close prices of both data are retained at this date. Conversely, if only Au is traded on May 25, 2003 whereas UDI is not traded at this date, then the close price of $A u$ at this date must be deleted, and vice versa. returns are defined as the first difference in the logarithms of daily metal commodities or UDI price then multiplied by 100 .

Table 1 reports the basic statistical characteristics of these seven metal commodities and UDI return series for all sample period (see Panel $A$ ), the pre-QE period (see Panel B), and the QE period (see Panel C). In regard to these three periods, the average daily return is positive for most of metal commodities whereas that is negative for UDI, implying that the UDI and each of the metal commodities take the opposite 


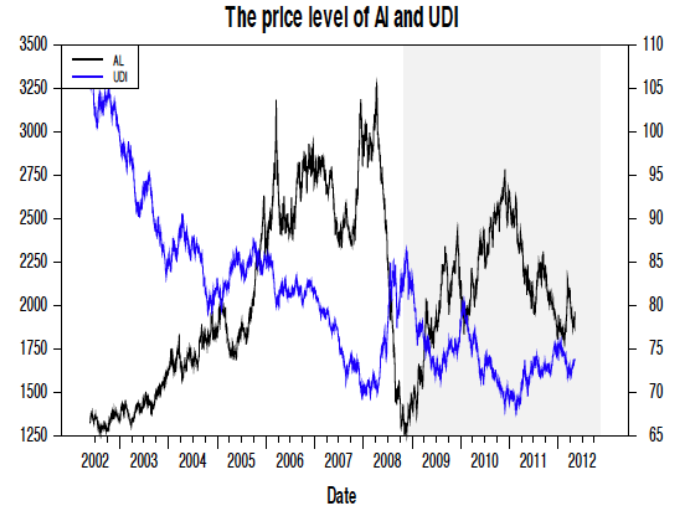

(a)

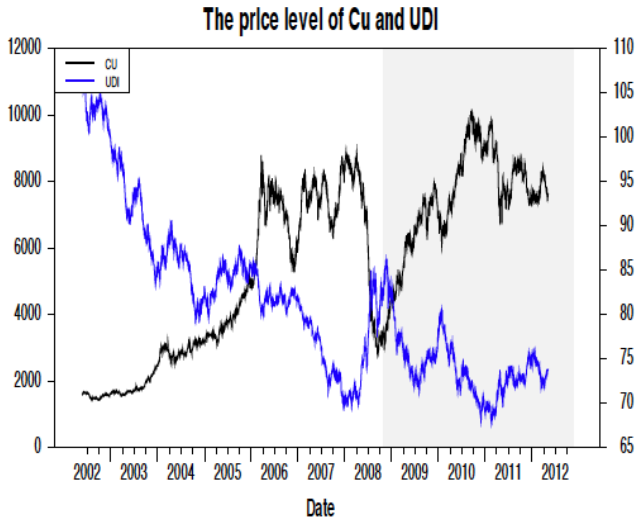

(c)

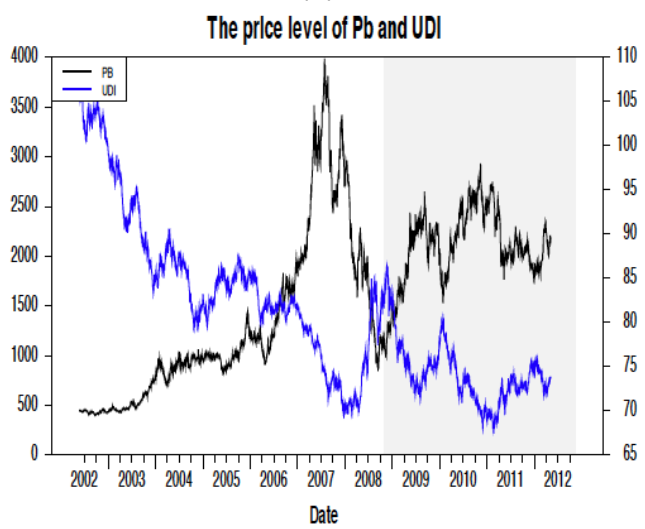

(e)

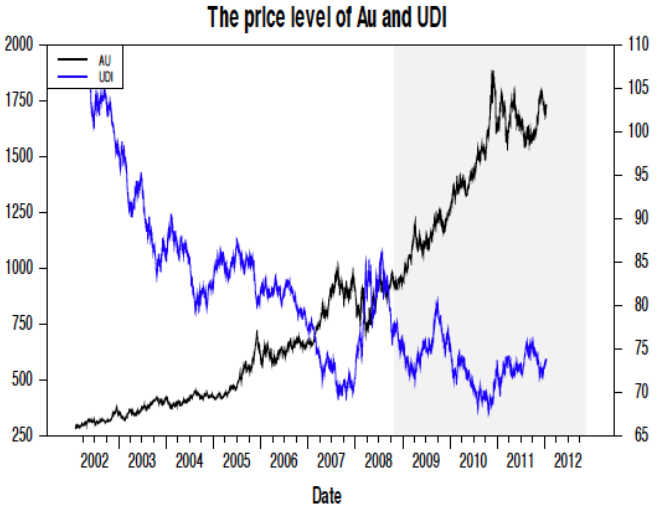

(b)

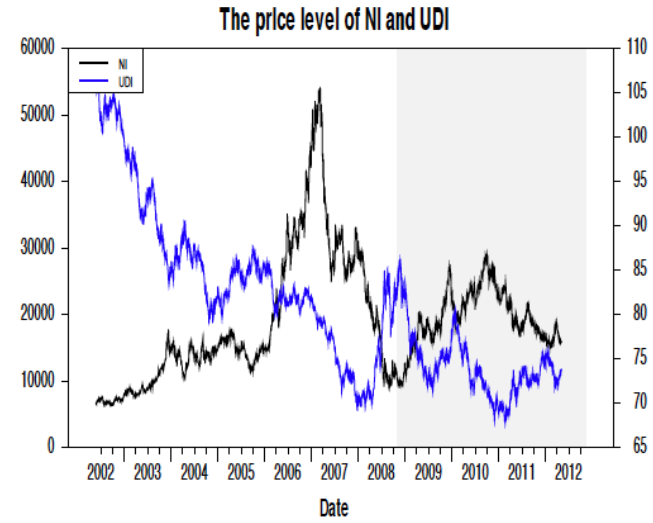

(d)

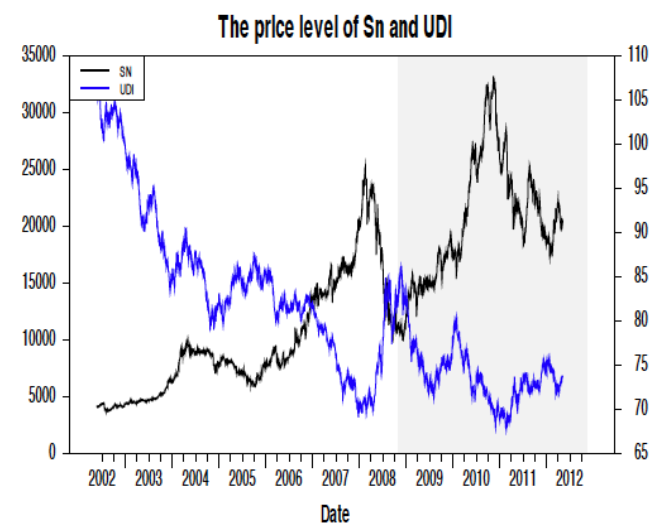

(f)

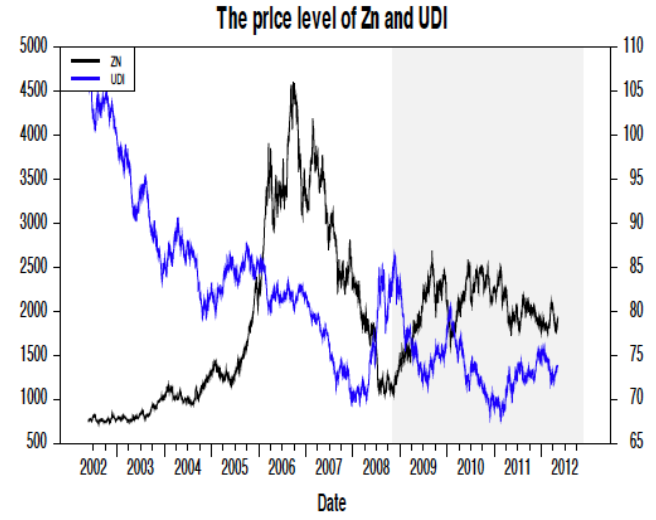

$(\mathbf{g})$

Figure 1: The levels of spot prices for overall period (a) Al-UDI (b) Au-UDI (c) Cu-UDI (d) Ni-UDI (e) Pb-UDI (f) Sn-UDI (g) ZnUDI pair of data, where the shade area denotes the period of QE execution. 


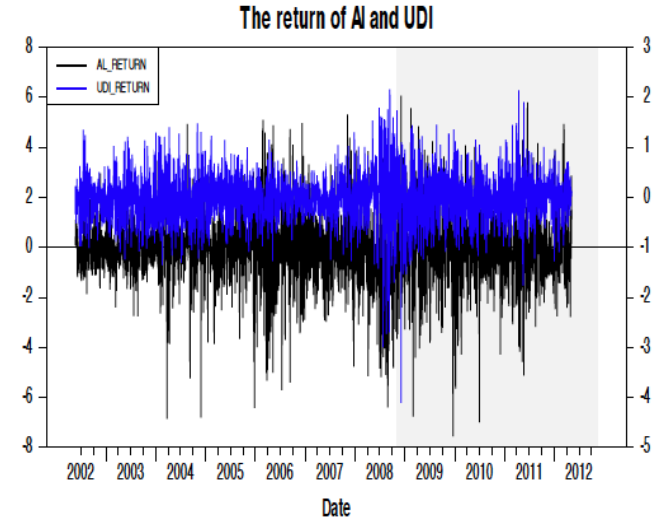

(a)

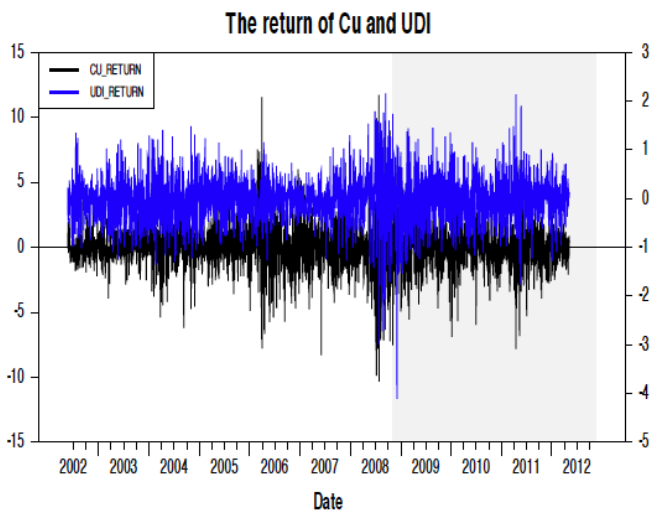

(c)

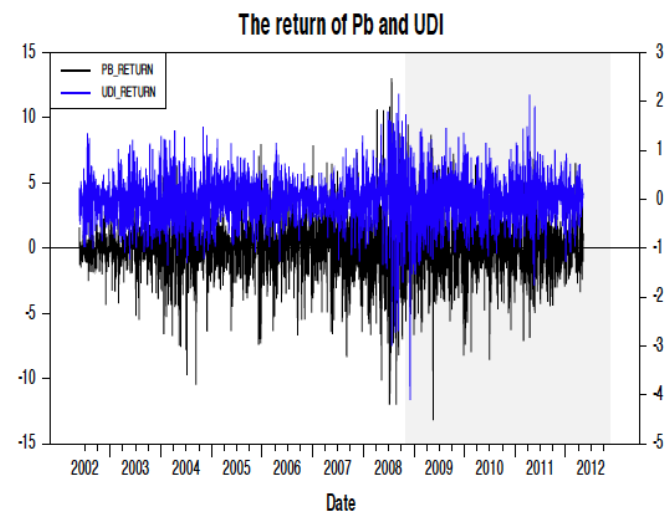

(e)

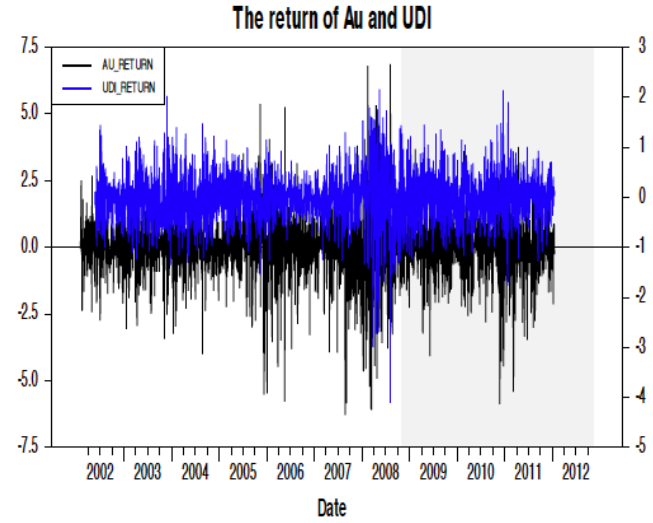

(b)

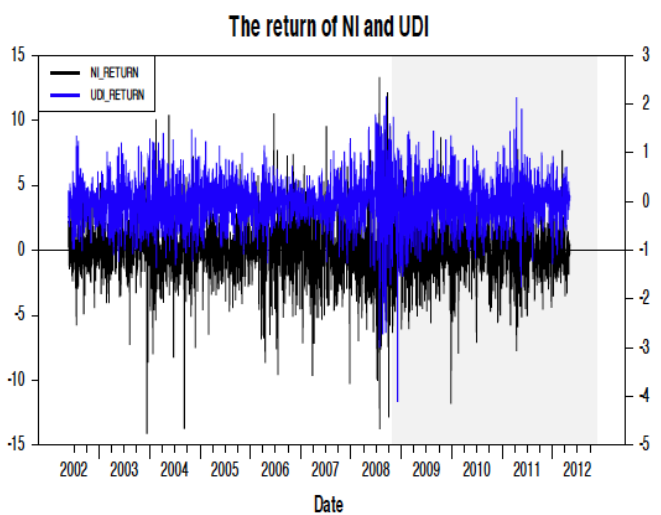

(d)

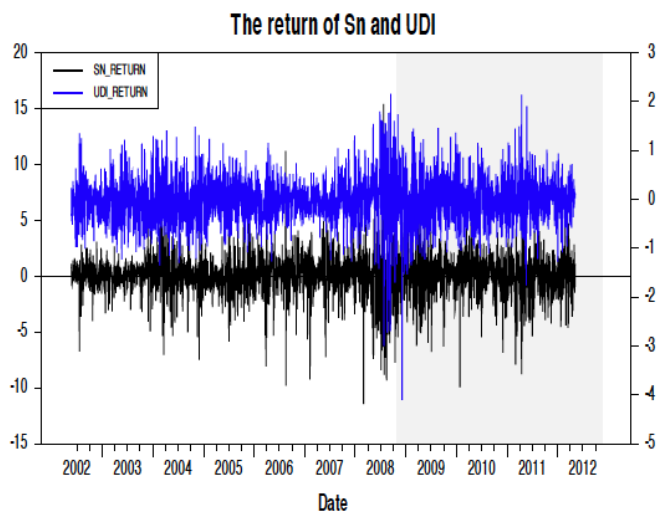

(f)

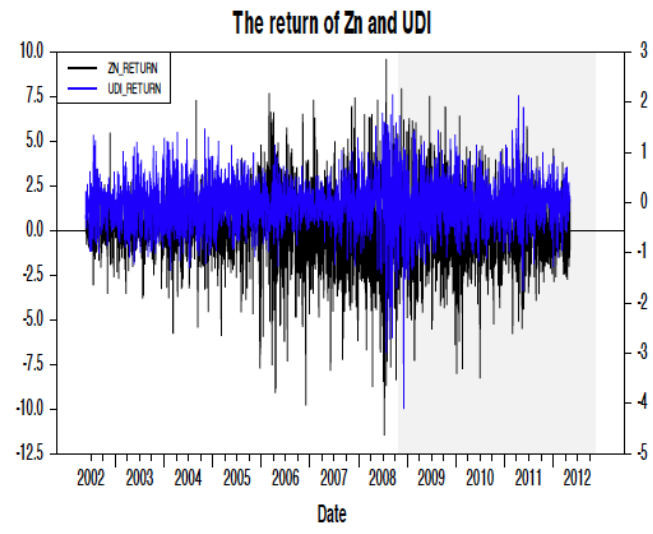

(g)

Figure 2: The return of spot prices for overall period (a) Al-UDI (b) Au-UDI (c) Cu-UDI (d) Ni-UDI (e) Pb-UDI (f) Sn-UDI (g) ZnUDI pair of data, where the shade area denotes the period of QE execution. 
direction on price level. This phenomenon can also be observed in Figure $\mathbf{1}^{10}$. Moreover, the standard deviation of all metal commodities is larger than that of UDI, inferring that the metal commodities are more volatile than UDI in price level. This phenomenon can also be found from the return scale of Figure 2, that is the return variation of metal commodity is larger than that of UDI. As reported from the coefficient of skewness, the excess kurtosis and J-B normality test statistics, all of the return series present left-skewed and the distribution of returns has larger, thicker tails than normal distribution. Thus they aren't normally distributed. Furthermore, the Ljung-Box $\mathrm{Q}^{2}(12)$ statistics for the squared returns are all significant at the $1 \%$ level and thus indicate that the return series exhibits linear dependence and strong $\mathrm{ARCH}$ effects. Hence, the preliminary analysis of the data suggests the use of a GARCH-family model to capture the fat tails and time-varying volatility found in these metal commodities and UDI returns series.

\section{EMPIRICAL RESULTS}

In this section, two bivariate asymmetric $\mathrm{GARCH}$ models (B-GJR-GARCH and B-EGARCH) are used to estimate the conditional variance and covariance of seven pairs of data for the periods of pre-QE and $Q E$; further, these results are utilized to explore both return and volatility spillover effects, the co-integration relation, the correlative relationship between these two markets, and the risk premium and leverage effect in each of these two markets.

\subsection{The Number of Lag for Mean and Variance Equations}

Before I investigate the above issues, I first explain why I choose the lag numbers of $\operatorname{VECM}(2)$ and $\operatorname{GARCH}(1,1)$ for mean and variance equations, respectively. Table 2 reports the Akaike information criterion (AIC) and Schwarz's Bayesian Criterion $(\mathrm{SBC})^{11}$ values of alternative lags for seven pairs of data. From Table 2, I can observe that, regarding seven pairs of data, the optimal lag number is one for AIC since the lag one owns the greatest value (4) of the total number of pairs of data that own the maximum value (in absolute value) of AIC among lags 1-6.

\footnotetext{
${ }^{10}$ The shaded areas in Figures 1 and 2 denote the period of QE execution.

${ }^{11}$ The Akaike information criterion (AIC) is a measure of the relative quality of a statistical model for a given set of data, and it can deal with the trade-off between the goodness of fit of the model and the complexity of the model. On the contrary, Schwarz's Bayesian Criterion (SBC) is based on the likelihood function. Notably, both AIC and SBC can provide a method for model selection.
}

Conversely, the optimal lag number is two for SBC since the lag two owns the greatest value (7) of the total number of pairs of data that own the maximum value (in absolute value) of SBC among lags 1-6. Notably, the maximum value (in absolute value) of SBC occurs at the lag 2 for all seven pairs of data, indicating that the optimal lag number should be two based on SBC. On the other hand, if the two time series are bound by some relationship in the long run then the VAR framework needs to be modified to allow consistent estimation of the relationships among the series. Hence, I select VECM (2) (vector error correction model with lag 2) model as the mean equation of this study. Moreover, Table 3 lists the loglikelihood values of alterative $\operatorname{GARCH}(p, q)$ models and their likelihood ratio test (LR) statistics besides $\operatorname{GARCH}(1,1)$ for seven metals and UDI. The LR test statistics is used to compare the fitting ability between $\operatorname{GARCH}(p, q)$ and $\operatorname{GARCH}(1,1)$ models. As shown in Table 3, the numbers in row Sum2 are greater that those in row Sum1 for most of lags, indicating that the fitting ability of $\operatorname{GARCH}(1,1)$ model is superior to that of $\operatorname{GARCH}(p, q)$. Therefore, I choose $\operatorname{GARCH}(1,1)$ as the specification of variance equation in this work.

\subsection{The Preliminary Analysis for Alternative Models}

Since both the B-GJR-GARCH and B-EGARCH models can be used to capture the leverage effect. However, which model, the B-GJR-GARCH or BEGARCH, is more suitable to be utilized to explore the above issues. Hence, before I explore the above issues, I perform an evaluation for these two bivariate GARCH models via the significance of model parameters. Basically, if one model such as BEGARCH model owns the greater the total number of pairs of data that a specified parameter being significant for most of parameters as compared with the other model such as B-GJR-GARCH model then the BEGARCH model has the better fitting ability.

Tables 4 and 5 respectively list the empirical results of B-GJR-GARCH and B-EGARCH models for seven metal-UDI pairs of data as the QE effect is considered. From Tables 4-5, I can observe that when the B-GJRGARCH and B-EGARCH models are compared 15 parameters $\left(\varphi_{131}^{\mathrm{BQE}}, \varphi_{131}^{\mathrm{QE}}, \varphi_{132}^{\mathrm{BQE}}, \varphi_{132}^{\mathrm{QE}}, \varphi_{211}^{\mathrm{BQE}}, \varphi_{211}^{\mathrm{QE}}, \varphi_{212}^{\mathrm{BQE}}\right.$, $\delta_{1}^{\mathrm{BQE}}, \delta_{2}^{\mathrm{QE}}, v_{1}^{\mathrm{BQE}}, v_{1}^{\mathrm{QE}}, v_{2}^{\mathrm{BQE}}, v_{2}^{\mathrm{QE}}, \omega_{12}^{\mathrm{BQE}}$ and $\left.\omega_{12}^{\mathrm{QE}}\right)$ in the B-EGARCH model whereas only 5 parameters $\left(\varphi_{212}^{\mathrm{QE}}\right.$, $\eta_{1}^{\mathrm{BQE}}, \eta_{1}^{\mathrm{QE}}, \eta_{2}^{\mathrm{BQE}}$ and $\left.\eta_{2}^{\mathrm{QE}}\right)$ in the B-GJR-GARCH model own the greater the total number of pairs of data that a specified parameter being significant. For 
Table 2: The AIC and SBC Values of Alternative Lags for Seven Pairs of Data

\begin{tabular}{|c|c|c|c|c|c|c|c|c|}
\hline Lag & \multicolumn{2}{|c|}{ Al-UDI } & \multicolumn{2}{|c|}{ Au-UDI } & \multicolumn{2}{|c|}{ Cu-UDI } & \multicolumn{2}{|c|}{ Ni-UDI } \\
\hline 1 & -49503.5 & -49421.1 & -50835.1 & -50752.8 & -48160.5 & -48078.1 & -46563.5 & -46481.1 \\
\hline 2 & -49511.4 & -49452.7 & -50843.2 & -50784.6 & -48179.7 & -48121.1 & -46559.9 & -46501.3 \\
\hline 3 & -49505.8 & -49423.7 & -50849.3 & -50767.2 & -48172.5 & -48090.5 & -46553.6 & -46471.5 \\
\hline \multirow[t]{3}{*}{6} & -49492.2 & -49339.7 & -50831.7 & -50679.2 & -48160.7 & -48008.2 & -46551.2 & -46398.7 \\
\hline & \multicolumn{2}{|c|}{ Pb-UDI } & \multicolumn{2}{|c|}{ Sn-UDI } & \multicolumn{2}{|c|}{ Zn-UDI } & \multicolumn{2}{|c|}{ Sum } \\
\hline & AIC & SBC & AIC & SBC & AIC & SBC & AIC & SBC \\
\hline 1 & -46865.7 & -46783.3 & -47914.4 & -47832.0 & -47498.3 & -47415.9 & 4 & 0 \\
\hline 4 & -46858.9 & -46753.3 & -47900.1 & -47794.6 & -47483.7 & -47378.1 & 0 & 0 \\
\hline 5 & -46851.3 & -46722.3 & -47894.9 & -47765.9 & -47478.5 & -47349.5 & 0 & 0 \\
\hline 6 & -46847.6 & -46695.1 & -47888.7 & -47736.2 & -47473.9 & -47321.5 & 0 & 0 \\
\hline
\end{tabular}

Note: 1. Bold font in each column of pairs of data denotes the maximum value (in absolute value) of AIC or SBC among lags 1-6. 2. The numbers in column AIC (resp. SBC) underneath Sum denote the total number of pairs of data that own the maximum value (in absolute value) of AIC (resp. SBC) for a specified lag. 4. The shade font in these number of column AIC (resp. SBC) underneath Sum denotes the greatest value of the total number of pairs of data among lags 1-6.

Table 3: The Log-Likelihood Values of Alterative GARCH(p,q) Models for Seven Metals and UDI

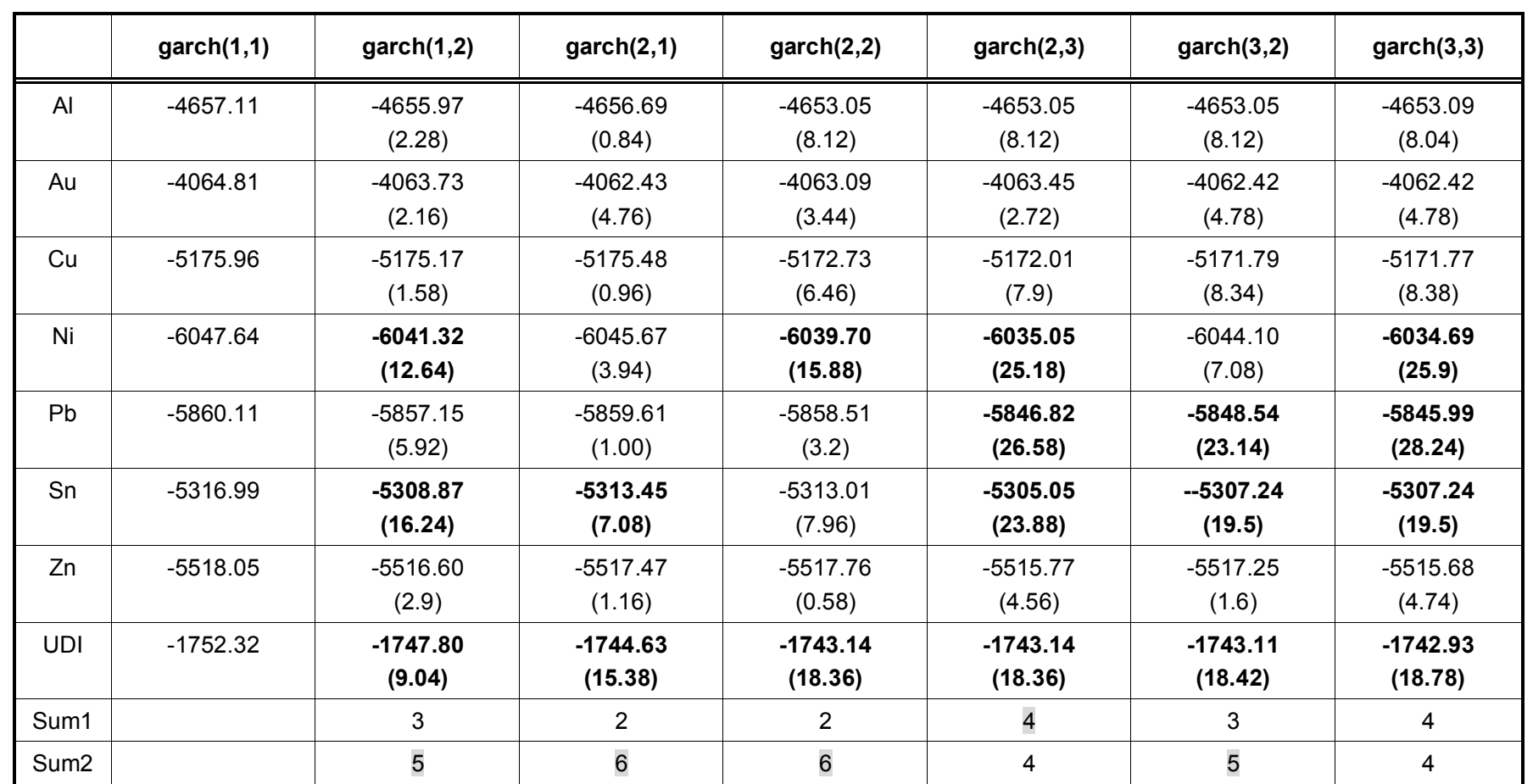

Note: 1. The numbers inside the bracket underneath the log-likelihood values under a specified GARCH(p,q) model denote the likelihood ratio test (LR) that test the null hypothesis of $\operatorname{GARCH}(1,1)$ against the alternative hypothesis of this specified $G A R C H(p, q) .2$. $L R=-2\left(L R_{r}-L_{R}\right) \sim \chi^{2}(m)$, where $L R_{r}$ and $L R_{u}$ are , respectively, the maximum value of the log-likelihood values under the null hypothesis of the restricted model, $A R(2)-G A R C H(1,1)$, and the alternative hypothesis of the unrestricted model, $\mathrm{AR}(2)-\mathrm{GARCH}(\mathrm{p}, \mathrm{q})$ and $\mathrm{m}$ is the number of the restricted parameters in the restricted model and equal to $p+q-2$. For example, the likelihood ratio test for the null hypothesis of $\operatorname{AR}(2)-G A R C H(1,1)$ model against the alternative hypothesis of $A R(2)-G A R C H(2,1)$. Restate, LR $=-2\left(L R_{r}-L_{u}\right) \sim \chi^{2}(1) .3$. The above likelihood ratio test is based on $A R(2)-G A R C H(p, q)$ model, $R_{t}=\varphi_{0}+\varphi_{1} R_{t-1}+\varphi_{2} R_{t-2}+\varepsilon_{t}, h_{t}=\omega_{1}+\sum^{p} \beta_{i} h_{t-i}+\sum^{4} \alpha_{\varepsilon_{t-j}^{2}}^{2}$. 4. The bold font denotes the likelihood ratio test is rejected at the $1 \%$ level. 5. The numbers in row Sum1 denote the total number of data that $A R(2)-G A R C H(p, q)$ is superior to $A R(2)-G A R C H(1,1)$. That is these numbers are the total number of data that reject the null hypotheses of likelihood ratio test. 6 . The numbers in row Sum2 denote the total number of data that $A R(2)-G A R C H(1,1)$ is superior to $A R(2)-G A R C H(p, q)$. 
Table 4: Empirical Results of B-GJR-GARCH Model for Seven Metal-UDI Pairs of Data

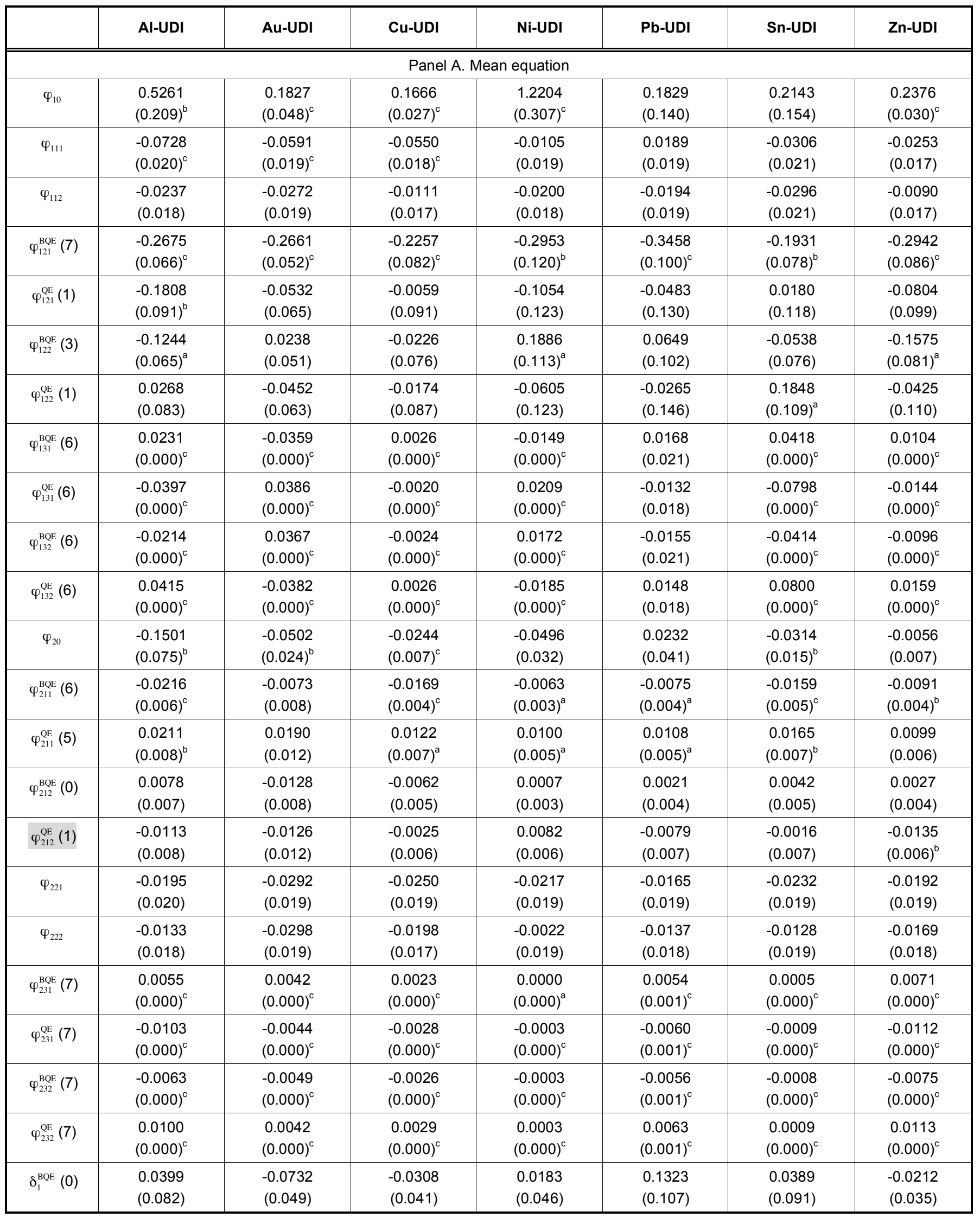


(Table 4). Continued.

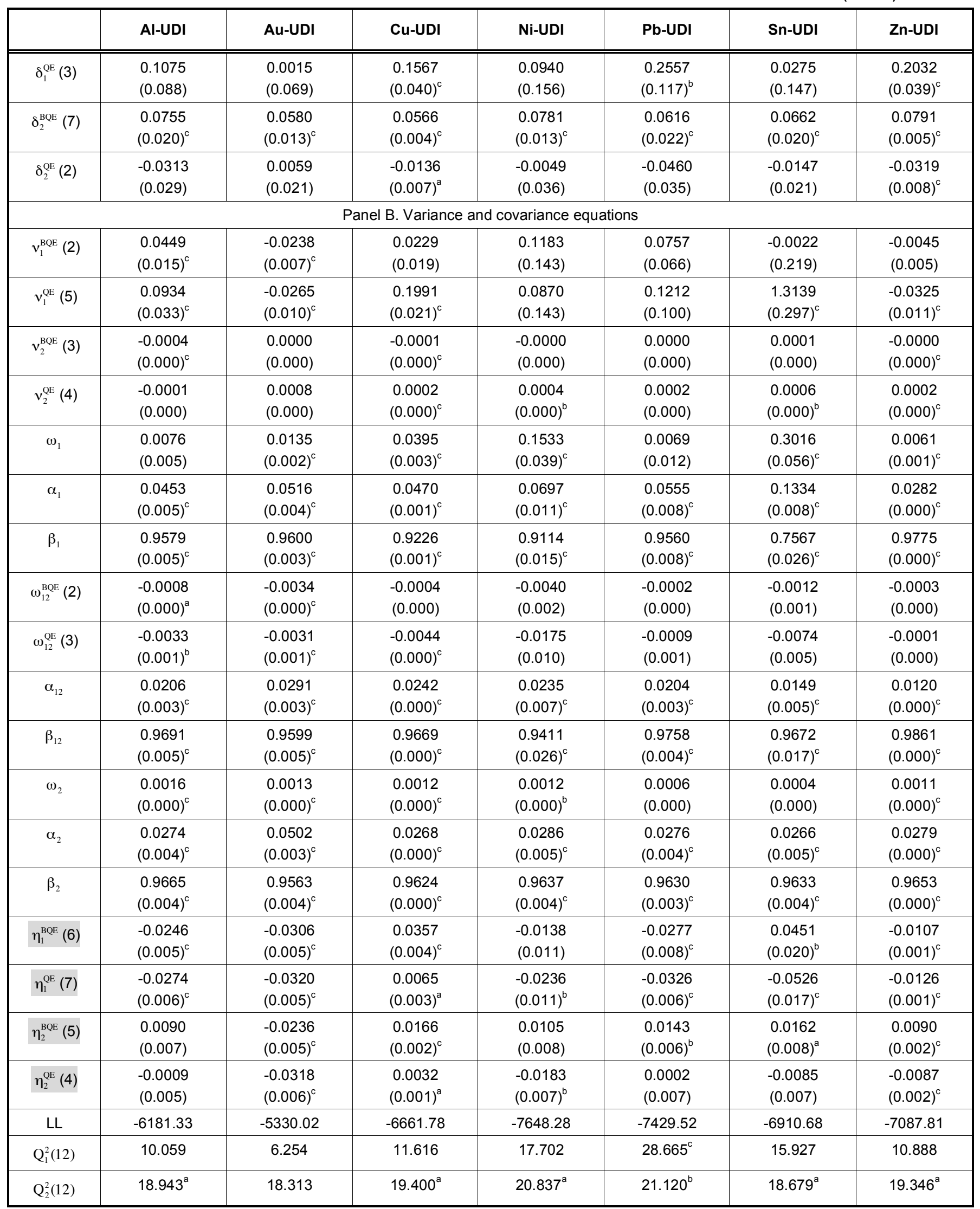

Note: 1. a, b and c denote significantly at the $10 \%, 5 \%$ and $1 \%$ levels, respectively. 2 . Numbers in parentheses at the row of parameters are standard errors. 3 . LL indicates the log-likelihood value. 4. The number inside the bracket that beside the parameter name denotes the total number of pairs of data that are significant at this parameter. Moreover, the parameters in shade font denote that this parameter owns the greater the total number of pairs of data that are significant at this parameter when B-GJR-GARCH and B-EGARCH models are compared each other. 
Table 5: Empirical Results of B-EGARCH Model for Seven Metal-UDI Pairs of Data

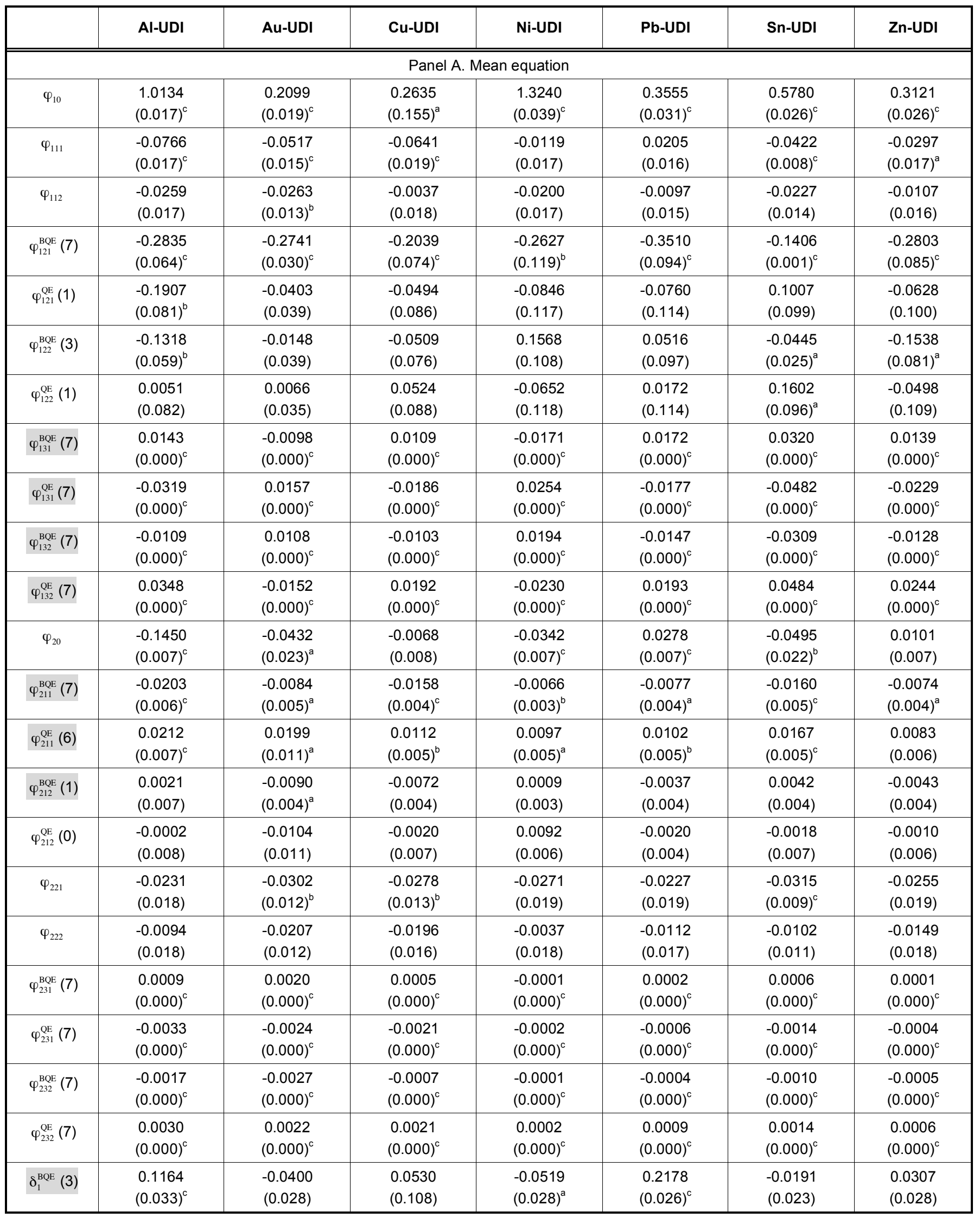


(Table 5). Continued.

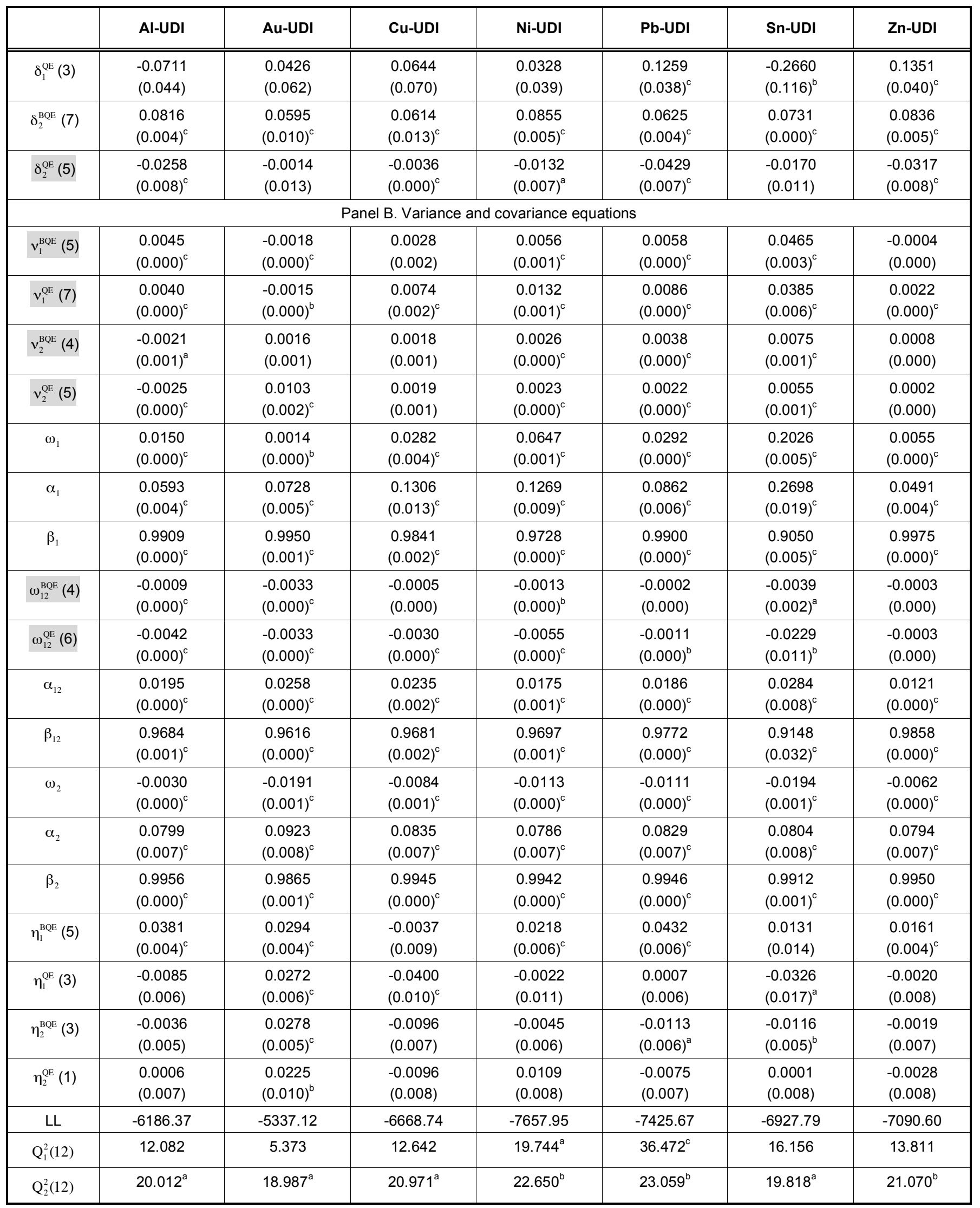

Note: 1. a, b and c denote significantly at the $10 \%, 5 \%$ and $1 \%$ levels, respectively. 2 . Numbers in parentheses at the row of parameters are standard errors. 3 . LL indicates the log-likelihood value. 4. The number inside the bracket that beside the parameter name denotes the total number of pairs of data that are significant at this parameter. Moreover, the parameters in shade font denote that this parameter owns the greater the total number of pairs of data that are significant at this parameter when B-GJR-GARCH and B-EGARCH models are compared each other. 
example, as shown in Table 4 parameter $\varphi_{131}^{\mathrm{BQE}}$ is all significant except for pb-UDI hence the total number of pairs of data that parameter $\varphi_{131}^{\mathrm{BQE}}$ being significant is equal to 6 for the B-GJR-GARCH model. On the contrary, as shown in Table 5 parameter $\varphi_{131}^{\mathrm{BQE}}$ is significant for all 7 pairs of data hence the total number of pairs of data that parameter $\varphi_{131}^{\mathrm{BQE}}$ being significant is equal to 7 for the B-EGARCH model. Owing to the above result, parameter $\varphi_{131}^{\mathrm{BQE}}$ in the $\mathrm{B}-\mathrm{EGARCH}$ model (7) owns the greater the total number of pairs of data that $\varphi_{131}^{\mathrm{BQE}}$ parameter being significant as compared with that parameter in the B-GJR-GARCH model (6). Hence, as the QE effect is considered the B-EGARCH model $(15)^{12}$ has the better fitting ability than B-GJRGARCH (5) since 15 is greater than 5. Thus, I will select the B-EGARCH model to explore the above issues. Finally, $Q_{1}^{2}(12)$ test statistics are not significant for most of seven pairs of data. Conversely, $\mathrm{Q}_{2}^{2}(12)$ test statistics are significant at the $10 \%$ level but the values of the statistics are significantly lower than those appearing in all panels of Table 1. These results indicate that the serial correlation has been significantly reduced in standard residuals, confirming that the alternative B-GARCH models addressed in this study is sufficient to correct the serial correlation of these seven pairs of data returns series in the conditional variance equation.

\subsection{The Exploration of Common Financial Phenomena}

Since the B-EGARCH model owns the better fitting ability, thus I will use the results of Table $\mathbf{5}$ to explore the above issues for the periods of pre-QE and $\mathrm{QE}$. Moreover, I divide the above issues into the following six categories ${ }^{13}$ : return spillover effect $\left(\varphi_{121}^{\mathrm{BQE}}, \varphi_{211}^{\mathrm{BQE}}, \varphi_{121}^{\mathrm{QE}}\right.$ and $\left.\varphi_{211}^{\mathrm{QE}}\right)$, volatility spillover effect $\left(v_{1}^{\mathrm{BQE}}, \boldsymbol{v}_{2}^{\mathrm{BQE}}\right.$, $v_{1}^{\mathrm{QE}}$ and $\left.v_{2}^{\mathrm{QE}}\right)$, risk premium $\left(\delta_{1}^{\mathrm{BQE}}, \delta_{2}^{\mathrm{BQE}}, \delta_{1}^{\mathrm{QE}}\right.$ and $\left.\delta_{2}^{\mathrm{QE}}\right)$, co-integrating relation $\left(\varphi_{131}^{\mathrm{BQE}}, \varphi_{231}^{\mathrm{BQE}}, \varphi_{131}^{\mathrm{QE}}\right.$ and $\left.\varphi_{231}^{\mathrm{QE}}\right)$, leverage effect $\left(\eta_{1}^{\mathrm{BQE}}, \eta_{2}^{\mathrm{BQE}}, \eta_{1}^{\mathrm{QE}}\right.$ and $\left.\eta_{2}^{\mathrm{QE}}\right)$ and correlative relation $\left(\omega_{12}^{\mathrm{BQE}} \text { and } \omega_{12}^{\mathrm{QE}}\right)^{14}$. Notably, regarding the return and volatility spillover effects the significance of corresponding parameters with lag 2 significantly decreases as compared with that with lag

\footnotetext{
${ }^{12}$ The number in the bracket beside the model denotes the total number of parameters that owns the greater the total number of pairs of data that are significant at this parameter when B-GJR-GARCH and B-EGARCH models are compared.

${ }^{13}$ Since it is hard to investigate these issues via the empirical results of Table $\mathbf{5}$, thus I only consider the parameters that are related to the above issues. For example, in Table $\mathbf{5}$ the parameters which superscripts are "BQE" and "QE".

${ }^{14}$ The parameters inside the bracket beside six issues are the parameters that are relate to the corresponding issues.
}

1. For instance, as reported in Table 5 parameter $\varphi_{121}^{\mathrm{BQE}}$ is significant for all seven pairs of data hence the total number of pairs of data that parameter $\varphi_{121}^{\mathrm{BQE}}$ being significant is equal to 7. Conversely, parameter $\varphi_{122}^{\mathrm{BQE}}$ is significant only for Al-UDI, Sn-UDI and Zn-UDI hence the total number of pairs of data that parameter $\varphi_{122}^{\mathrm{BQE}}$ being significant is equal to 3 . These results indicate that parameter $\varphi_{121}^{\mathrm{BQE}}$ owns the greater the total number of pairs of data as compared with parameter $\varphi_{122}^{\mathrm{BQE}}$. Hence I use the parameters with lag 1 to explore the above issues. Moreover, regarding co-integrating relation I also consider the parameters with lag 1 .

Subsequently, the empirical results of Table 5 is used to explore the above six types of issues for the periods of pre-QE and $\mathrm{QE}$. The first category explores the return spillover effect between the metal market in LME and US exchange rate market. The values of parameter $\varphi_{121}^{\mathrm{BQE}}$ range from $-0.3510(\mathrm{~Pb}-\mathrm{UDI})$ to -0.1406 (Sn-UDI), whereas those of parameter $\varphi_{121}^{\mathrm{QE}}$ are between -0.1907 (Al-UDI) and 0.1007 (Sn-UDI). Notably, the values of parameters $\varphi_{121}^{\mathrm{BQE}}$ and $\varphi_{121}^{\mathrm{QE}}$ are negative for all seven pairs of data except for $\varphi_{121}^{\mathrm{QE}}$ of Sn-UDI. Moreover, the values of parameter $\varphi_{121}^{\mathrm{BQE}}$ significantly exhibit negative for all pairs of data whereas those of parameter $\varphi_{121}^{\mathrm{QE}}$ are not significant, with the exception of Al-UDI. These phenomena can be inferred the fact that from the US exchange rate market to metal market a negative return spillover effect significantly subsists for the period pre-QE. However, as the $\mathrm{QE}$ is executed this return spillover effect disappears. On the contrary, the values of parameter $\varphi_{211}^{\mathrm{BQE}}$ range from -0.0203 (Al-UDI) to -0.0066 (Ni-UDI), whereas those of parameter $\varphi_{211}^{\mathrm{QE}}$ are between 0.0083 ( $\mathrm{Zn}-\mathrm{UDI}$ ) and 0.0212 (AI-UDI). Notably, all the values of parameter $\varphi_{211}^{\mathrm{BQE}}$ are significantly negative whereas most of the values of parameter $\varphi_{211}^{\mathrm{QE}}$ are significantly positive. These results imply that from the metal market to US exchange rate market a negative return spillover effect significantly subsists for the pre-QE period for all pairs of data. However, as the QE is executed this negative return spillover effect has been reversed to positive.

The second category investigates the volatility spillover effect between the metal market in LME and US exchange rate market. The values of parameter $v_{1}^{\mathrm{BQE}}$ range from -0.0018 (Au-UDI) to 0.0465 (Sn-UDI) whereas those of parameter $v_{1}^{\mathrm{QE}}$ are between -0.0015 (Au-UDI) and 0.0385 (Sn-UDI). Notably, all the values of parameters $v_{1}^{\mathrm{BQE}}$ and $v_{1}^{\mathrm{QE}}$ are significantly positive for most of pairs of data, but nearly approach zero 
since the values of these two parameters are less than 0.01 for most of pairs of data, suggesting that the volatility spillover effect from the US exchange rate market to the metal market seems not to exist between these two markets during these two periods. On the other hand, the values of parameter $v_{2}^{\mathrm{BQE}}$ range from -0.0021 (AI-UDI) to 0.0075 (Sn-UDI) whereas those of parameter $v_{2}^{\mathrm{QE}}$ are between -0.0025 (Al-UDI) and 0.0103 (Au-UDI). Notably, all the values of parameters $v_{2}^{\mathrm{BQE}}$ and $v_{2}^{\mathrm{QE}}$ are positive for most of pairs of data, but nearly approach zero since the values of these two parameters are less than 0.01 for most of pairs of data, hinting that the volatility spillover effect from the metal market to US exchange rates market seems not to exist between these two markets during these two periods.

The third category explores the risk premium in each of these two markets. As to the volatility feedback effect, the values of parameters $\delta_{1}^{\mathrm{BQE}}$ are significanlly positive only for AI-UDI (0.1164) and Pb-UDI (0.2178) whereas the values of parameters $\delta_{1}^{\mathrm{QE}}$ are significanlly positive only for Pb-UDI (0.1259) and Zn-UDI (0.1351), indicating that regarding the metal market the risk premium induced by volatility is not measured during these two periods. On the contrary, the values of parameter $\delta_{2}^{\mathrm{BQE}}$ range from 0.0595 (Au-UDI) to 0.0855 (Ni-UDI) and are significantly positive for all pairs of data, whereas the values of parameter $\delta_{2}^{\mathrm{QE}}$ are negative for all pairs of data. This result indicates that regarding the US exchange rate market the risk premium induced by volatility is measured only for the period pre-QE, and further infers that risk-averse investors in US exchange rate market need a higher expected return as the risk is higher. However, as the $\mathrm{QE}$ is executed the risk premium induced by volatility is not measured. The fourth category explores the cointegration relation in these two markets. The values of parameter $\varphi_{131}^{\mathrm{BQE}}$ range from -0.0171 (Ni-UDI) to 0.0320 (Sn-UDI) whereas those of parameter $\varphi_{131}^{\mathrm{QE}}$ are between -0.0482 (Sn-UDI) and 0.0254 (Ni-UDI). Notably, the values of parameters $\varphi_{131}^{\mathrm{BQE}}$ and $\varphi_{131}^{\mathrm{QE}}$ are significantly for all pairs of data. Moreover, regarding each of pairs of data, the values of $\varphi_{131}^{\mathrm{QE}}$ are greater than those of $\varphi_{131}^{\mathrm{BQE}}$ in absolute value and the sign of these two parameters is opposite. These results indicate that the co-integration relation significantly exists in the metal market for pre-QE and QE periods. Moreover, as the $\mathrm{QE}$ is executed the speed of adjustment back to equilibrium becomes greater and the direction of this adjustment is reversed. As to parameters $\varphi_{231}^{\mathrm{BQE}}$ and $\varphi_{231}^{\mathrm{QE}}$, the values of parameter $\varphi_{231}^{\mathrm{BQE}}$ range from -0.0001 (Ni-UDI) to 0.0020 (Au-UDI) whereas those of parameter $\varphi_{231}^{\mathrm{QE}}$ are between -0.0033 (Al-UDI) and -0.0002 (Ni-UDI). Even through the values of parameters $\varphi_{231}^{\mathrm{BQE}}$ and $\varphi_{231}^{\mathrm{QE}}$ are significantly for all pairs of data, but they all approach zero since the values of these two parameters are less than 0.01 for all seven pairs of data, indicating that the co-integration relation does not exists in US exchange rates market for these two periods. The fifth category explores the leverage effect in these two markets. All the values of parameters $\eta_{1}^{\mathrm{BQE}}$ are not significanlly negative whereas the values of parameters $\eta_{1}^{\mathrm{QE}}$ are significanlly negative only for Cu-UDI (-0.0400) and Sn-UDI (-0.0326), indicating that the leverage effect does not exist in metal market for pre-QE and QE periods. The same phenomena are also discovered in US exchange rates market since the values of parameters $\eta_{2}^{\mathrm{BOE}}$ are significanlly negative only for Pb-UDI $(-0.0113)$ and Sn-UDI (-0.0116) whereas all the values of parameters $\eta_{2}^{\mathrm{QE}}$ are not significanlly negative.

The last category explores the correlative relation between these two markets. The values of parameter $\omega_{12}^{\mathrm{BOE}}$ range from -0.0039 (Sn-UDI) to $-0.0002(\mathrm{~Pb}-$ UDI) whereas those of parameter $\omega_{12}^{\mathrm{QE}}$ are between -0.0229 (Sn-UDI) and -0.0003 (Zn-UDI). Notably, all the values of parameters $\omega_{12}^{\mathrm{BQE}}$ and $\omega_{12}^{\mathrm{QE}}$ are negative. Moreover, the values of parameter $\omega_{12}^{\mathrm{QE}}$ are greater than those of parameter $\omega_{12}^{\mathrm{BQE}}$ in absolute value for most pairs of data. These phenomena indicate that the price trend of commodities in the metal market is opposite that of the US exchange rate market. Moreover, the degree of negative correlative relationship is more obvious for the period of $Q E$ as compared with the period pre-QE. Figure $3^{15}$ illustrates the trend of the conditional correlation ${ }^{16}$ between the metal market and US exchange rate market estimated by B-EGARCH model for these seven pairs of data: I can observe that the values of conditional correlation coefficients are negative for most of the time and for all seven pairs of data. Moreover, the values of conditional correlation coefficients for the period of $Q E$ are obviously greater than those for the period pre-QE in absolute value for most pairs of data. Table 6 lists the conditional correlation coefficients estimated by B-GJRGARCH and B-EGARCH models for these seven pairs of data for all sample period (see Panel $A$ ), the period pre-QE (see Panel B), and the period of QE (see Panel C). With regard to these three periods, since the results

\footnotetext{
${ }^{15}$ The shade area in Figure 3 denotes the period of QE executed.

${ }^{16}$ The conditional correlation in Figure 3 and Table $\mathbf{6}$ is defined as $\rho_{12, t}=h_{12, t} / \sqrt{h_{11, t} \cdot h_{22, t}}$ where $h_{12, t}$ denotes the covariance between the first and second assets whereas $h_{11, t}$ and $h_{2,2}$ are respectively the variances of the first and second assets. Please see equation (3) for more details.
} 


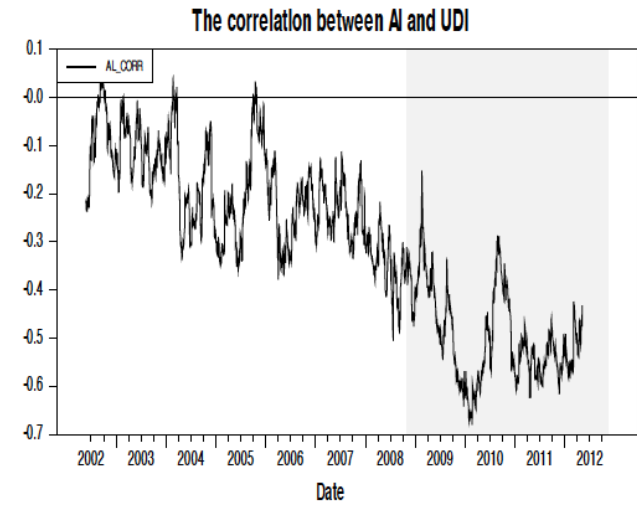

(a)

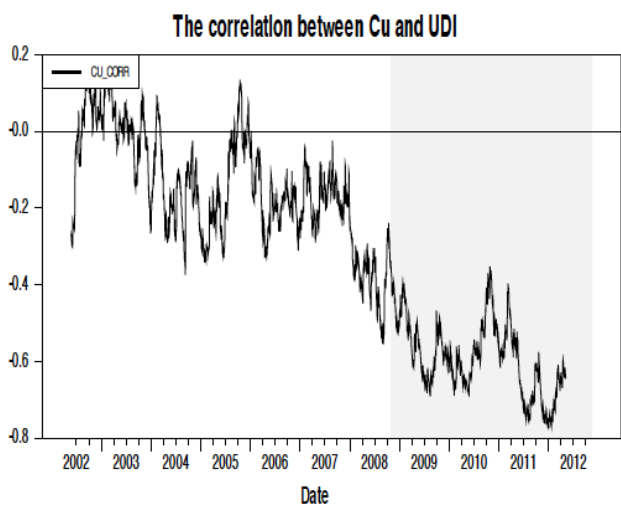

(c)

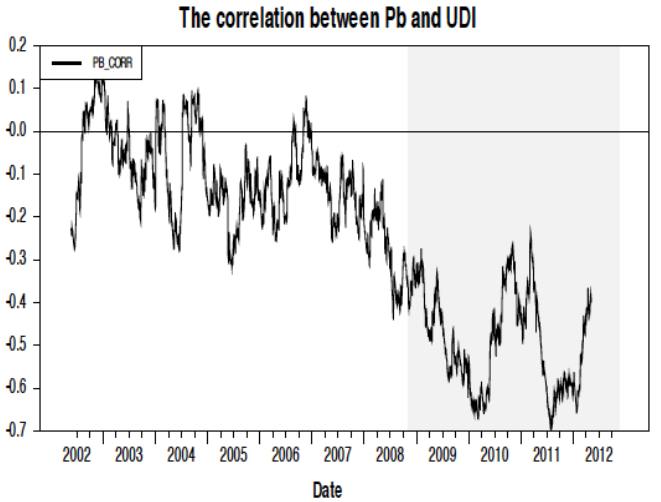

(e)

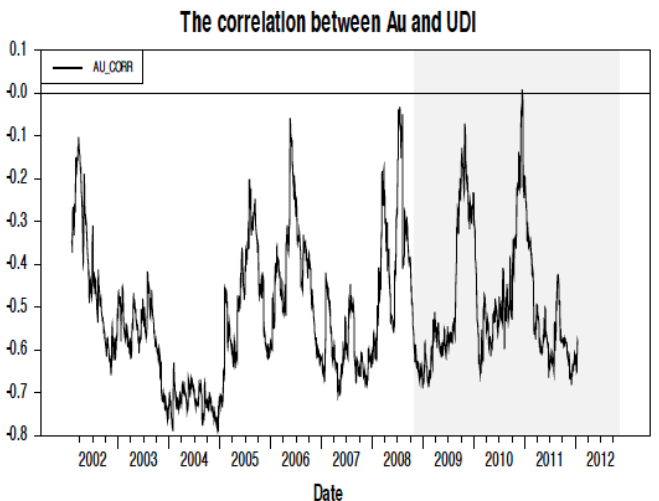

(b)

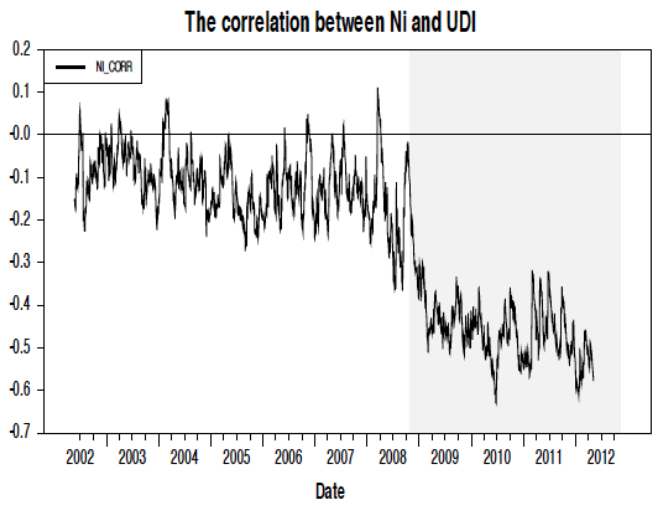

(d)

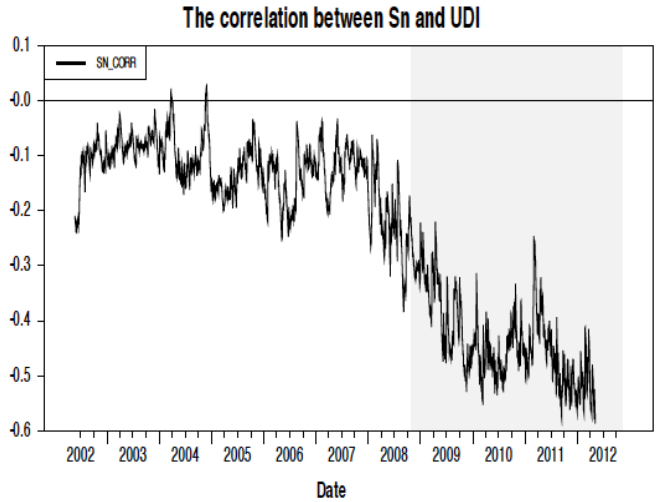

(f)

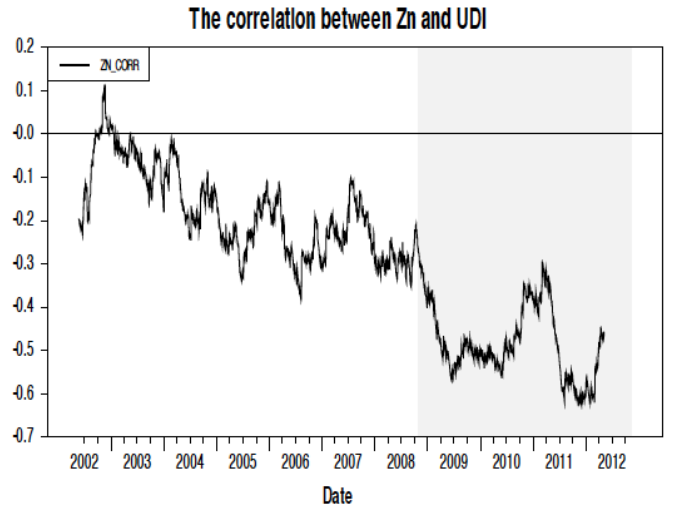

(g)

Figure 3: The conditional correlation between metal market and US exchange rates market estimated by the B-EGARCH-MX model for overall period (a) Al-UDI (b) Au-UDI (c) Cu-UDI (d) Ni-UDI (e) Pb-UDI (f) Sn-UDI (g) Zn-UDI pair of data, where the shade area denotes the period of $Q E$ execution. 
Table 6: The Conditional Correlation of Seven Metal-UDI Pairs of Data for B-GJR-GARCH and B-EGARCH Models

\begin{tabular}{|c|c|c|c|c|c|c|c|c|}
\hline & \multicolumn{4}{|c|}{ B-GJR-GARCH } & \multicolumn{4}{|c|}{ B-EGARCH } \\
\hline \multicolumn{9}{|c|}{ Panel A. The Overall period (2601 observations) } \\
\hline Al-UDI & -0.2945 & 0.1827 & -0.6807 & 0.0734 & -0.2928 & 0.1816 & -0.6646 & 0.0638 \\
\hline Au-UDI & -0.5118 & 0.1590 & -0.7891 & 0.0022 & -0.5023 & 0.1533 & -0.8531 & -0.0247 \\
\hline Pb-UDI & -0.2442 & 0.2170 & -0.6956 & 0.2234 & -0.2439 & 0.2179 & -0.6943 & 0.2088 \\
\hline Sn-UDI & -0.2321 & 0.1655 & -0.5866 & 0.0662 & -0.2190 & 0.1643 & -0.6109 & 0.1390 \\
\hline Zn-UDI & -0.2824 & 0.1701 & -0.6283 & 0.1286 & -0.2830 & 0.1706 & -0.6595 & 0.1409 \\
\hline \multicolumn{9}{|c|}{ Panel B. The period of pre-QE (1616 observations) } \\
\hline Cu-UDI & -0.1267 & 0.1366 & -0.4779 & 0.1644 & -0.1303 & 0.1340 & -0.5113 & 0.1617 \\
\hline $\mathrm{Ni}-U \mathrm{DI}$ & -0.1110 & 0.0726 & -0.3637 & 0.1062 & -0.1093 & 0.0779 & -0.3997 & 0.0933 \\
\hline Pb-UDI & -0.1015 & 0.1181 & -0.4767 & 0.2234 & -0.0987 & 0.1154 & -0.5075 & 0.2088 \\
\hline Sn-UDI & -0.1158 & 0.0574 & -0.3397 & 0.0662 & -0.1066 & 0.0632 & -0.3636 & 0.1390 \\
\hline Zn-UDI & -0.1709 & 0.0909 & -0.3662 & 0.1286 & -0.1698 & 0.0888 & -0.3521 & 0.1409 \\
\hline \multicolumn{9}{|c|}{ Panel C. The QE period (985 observations) } \\
\hline Al-UDI & -0.4867 & 0.0962 & -0.6807 & -0.1467 & -0.4901 & 0.0880 & -0.6646 & -0.1841 \\
\hline Au-UDI & -0.4733 & 0.1604 & -0.6932 & 0.0022 & -0.4665 & 0.1552 & -0.7209 & -0.0247 \\
\hline
\end{tabular}

Note: 1. Shade font denotes the maximum value of mean correlation in absolute value among two sub-periods (the periods of pre-QE and $Q E$ ).

estimated by these three models are very similar, I choose the results estimated by the B-EGARCH model to explore the correlative relationship between the metal market and US exchange rates market. The mean of conditional correlation coefficients ranges from -0.5023 (Au-UDI) to -0.2190 (Sn-UDI) for the overall period. Moreover, the mean of conditional correlation coefficients ranges from -0.5241 (Au-UDI) to -0.0987 $(\mathrm{Pb}-\mathrm{UDI})$ for the period pre-QE, whereas they are between -0.5576 (Cu-UDI) and -0.4036 (Sn-UDI) during the period of QE. Notably, the mean values of conditional correlation coefficients are negative for all seven pairs of data. Moreover, the mean values of conditional correlation coefficients for the period of $\mathrm{QE}$ are obviously greater than those for the period pre-QE in absolute value for most of the pairs of data. These results imply that the price trend of commodities in the metal market is opposite that of the US exchange rate market. Moreover, the degree of negative correlative relationship is more obvious for the period of QE as compared with the period pre-QE. These phenomena are consistent with those in the empirical results of parameters $\omega_{12}^{\mathrm{BQE}}$ and $\omega_{12}^{\mathrm{QE}}$. To sum up, I can presume that the price of commodities in the metal market is significantly affected by the price of USD in the US exchange rate market and their price levels move in opposite directions, contributing to a negative correlation between these two markets.

From the above discussion, I obtain the following conclusion ${ }^{17}$. That is as the $Q E$ is executed some financial phenomena are changed significantly. These financial phenomena include the return spillover effect from US exchange rates market to metal market in

\footnotetext{
${ }^{17}$ In the future research, I will use the commodities in the energy market to explore the issues addressed by this study again since the commodities in this market are also valued by US dollar. These results will be used to check the
} robustness of statistical results found in this study. 
LME since the negative return spillover effect disappears, and from metal market to US exchange rates market since the negative return spillover is changed into positive one; the co-integration relation in the metal market since the speed of adjustment back to equilibrium becomes greater and the direction of this adjustment is reversed; the risk premium in US exchange rates market since the volatility feedback effect disappears; and the correlative relation between these two markets since the degree of negative correlative relationship becomes more obvious. As to the remainder financial phenomena, they are similar for the periods of pre-QE and $\mathrm{QE}$. For example, the volatility spillover effect between these two markets, the risk premium in the metal market, the co-integration relation in the US exchange rates market, and the leverage effect in these two markets all don't exist during these two periods.

\section{CONCLUSION}

In this study, the vector error correction model (VECM) with lag 2 is used to take into account any cointegrating relationships between two variables. As to the bivariate variance-covariance specification, two asymmetric types of bivariate GARCH models are used to estimate the conditional variance and covariance of seven pairs of data for the periods of pre-QE and QE; further, these results are utilized to explore how some financial phenomena are changed as the $Q E$ is executed. These seven pairs of data are composed of the commodities in the metal market of LME and the UDI representing the US exchange rates market. These financial phenomena include both return and volatility spillover effects, and the correlative relationship between these two markets, and the cointegration relation, the risk premium and leverage effect in each of these two markets.

The empirical findings can be summarized as follows. As the $\mathrm{QE}$ is executed some financial phenomena are changed significantly. For example, the return spillover effect from US exchange rates market to metal market in LME since the negative return spillover effect disappears, and from metal market to US exchange rates market since the negative return spillover is changed into positive one; the co-integration relation in metal market since the speed of adjustment back to equilibrium becomes greater and the direction of this adjustment is reversed; the risk premium in US exchange rates market since the volatility feedback effect disappears; and the correlative relation between these two markets since the degree of negative correlative relationship becomes more obvious. As to the remainder financial phenomena, they are similar for the periods of pre-QE and QE.

Based on the above findings regarding the $Q E$ policy be implemented, several important policy implications are proposed in this study, and are expressed as follows. First, as shown in the result of the return spillover effect, the investors can predict the return of US exchange rate market today from the return of metal market in LME yesterday. For example, the negative return spillover from the metal market to US exchange rate market is changed into positive one as the $Q E$ is executed, indicating that if the value of return for metal market in LME increased (resp. decreased) yesterday, then that for US exchange rate market will decrease (resp. increase) today. However, as the $\mathrm{QE}$ is executed the above phenomena will change. That is, if the value of return for metal market in LME increased (resp. decreased) yesterday, then that for US exchange rate market will also increased (resp. decreased) today. Second, as reported in the result of correlative relation, the investors can predict the price trend of commodities in the metal market from that in US exchange rate market and vice versa. For instance, if the USD depreciates (appreciate) then the price of metal commodities will increase (decrease). Notably, as the QE is executed the above two phenomena are more obvious. Third, as observed from the results of the volatility feedback effect, investors should invest in the US exchange rate market for preQE period since they can earn a higher expected return due to the greater market risk. However, as the QE is performed, the investors should terminate the investment since they can't earn the higher expected return.

\section{REFERENCES}

Allen, D.E., Amrama, R. and McAleer, M. 2013. "Volatility spillovers from the Chinese stock market to economic neighbours." Mathematics and Computers in Simulation 94: 238-257. http://dx.doi.org/10.1016/j.matcom.2013.01.001

Antonakakis, N. 2012. "Exchange return co-movements and volatility spillovers before and after the introduction of euro." Journal of International Financial Markets, Institutions \& Money 22(5) 1091-1109. http://dx.doi.org/10.1016/j.intfin.2012.05.009

Baba, Y., Engle, R.F., Kraft, D.K. and Kroner, K. 1990. "Multivariate simultaneous generalized ARCH." Unpublished Manuscript, University of California.

Dean, W.G., Faff, R.W. and Loudon, G.F. 2010. "Asymmetry in return and volatility spillover between equity and bond markets in Australia." Pacific-Basin Finance Journal 18(3): 272-289. http://dx.doi.org/10.1016/j.pacfin.2009.09.003 
Efron, B. 1979. "Bootstrap Methods: Another Look at the Jackknife." The Annals of Statistics 7(1): 1-26. http://dx.doi.org/10.1214/aos/1176344552

Fama, E. 1965. "The behavior of stock market prices." Journal of Business 38(1): 34-105. http://dx.doi.org/10.1086/294743

Glosten, L.R., Jagannathan, R. and Runkle, D.E. 1993. "On the relation between the expected value and the volatility of the nominal excess return on stocks." Journal of Finance 48(5): 1779-1801. http://dx.doi.org/10.1111/j.1540-6261.1993.tb05128.x

Jarque, C.M. and Bera, A.K. 1987. "A test for normality of observations and regression residuals." International Statistics Review 55(2): 163-172. http://dx.doi.org/10.2307/1403192

Karras, G. 2013. "Asymmetric effects of monetary policy with or without Quantitative Easing: Empirical evidence for the US." The Journal of Economic Asymmetries 10(1): 1-9. http://dx.doi.org/10.1016/j.jeca.2013.04.001

Kitamura, Y. 2010. "Testing for intraday interdependence and volatility spillover among the euro, the pound and the Swiss franc markets." Research in International Business and Finance 24(2): 158-171. http://dx.doi.org/10.1016/j.ribaf.2009.11.002

Lee, Y.H. 2013. "Global and regional range-based volatility spillover effects." Emerging Markets Review 14: 1-10. http://dx.doi.org/10.1016/j.ememar.2012.09.007

Lyonnet, V. and Werner, R. 2012. "Lessons from the Bank of England on 'quantitative easing' and other 'unconventional' monetary policies." International Review of Financial Analysis 25: 94-105. http://dx.doi.org/10.1016/j.irfa.2012.08.001

Mandelbrot, B. 1963. "The variation of certain speculative prices." Journal of Business 36(4): 394-419. http://dx.doi.org/10.1086/294632

McMillan, D.G. and Speight, A.E.H. 2010. "Return and volatility spillovers in three euro exchange rates." Journal of Economics and Business 62(2): 79-93. http://dx.doi.org/10.1016/j.jeconbus.2009.08.003

Mensi, W., Beljid, M., Boubaker, A. and Managi, S. 2013. "Correlations and volatility spillovers across commodity and stock markets: Linking energies, food, and gold." Economic Modelling 32: 15-22. http://dx.doi.org/10.1016/j.econmod.2013.01.023

Merton, R.C. 1980. "On estimating the expected return on the market: an exploratory investigation." Journal of Financial Economics 8(4): 323-361. http://dx.doi.org/10.1016/0304-405X(80)90007-0
Moschini, G.C. and Myers, R.J. 2002. "Testing for constant hedge ratios in commodity markets: a multivariate GARCH approach." Journal of Empirical Finance 9(5): 589-603. http://dx.doi.org/10.1016/S0927-5398(02)00012-9

Nakazono, Y. and Ueda, K. 2013. "Policy commitment and market expectations: Lessons learned from survey based evidence under Japan's quantitative easing policy." Japan and the World Economy 25: 102-113. http://dx.doi.org/10.1016/j.japwor.2013.03.004

Nelson, D.B. 1991. "Conditional heteroskedasticity in asset returns: a new approach." Econometrica 59: 347-370. http://dx.doi.org/10.2307/2938260

Schenkelberg, H. and Watzka, S. 2013. "Real effects of quantitative easing at the zero lower bound: Structural VAR-based evidence from Japan." Journal of International Money and Finance 33: 327-357. http://dx.doi.org/10.1016/j.jimonfin.2012.11.020

Singh, P., Kumar, B. and Pandey, A. 2010. "Price and volatility spillovers across North American, European and Asian stock markets." International Review of Financial Analysis 19(1): 55-64. http://dx.doi.org/10.1016/j.irfa.2009.11.001

Skintzi, V.D. and Refenes, A.N. 2006. "Volatility spillovers and dynamic correlation in European bond markets." Journal of International Financial Markets, Institutions \& Money 16(1): 23-40.

http://dx.doi.org/10.1016/j.intfin.2004.12.003

Su, J.B. 2014. "The interrelation of stock markets in China, Taiwan and Hong Kong and their constructional portfolio's value-atrisk estimate." Journal of Risk Model Validation 8(4): 69-127. http://dx.doi.org/10.21314/JRMV.2014.130

Su, J.B. 2015. "Value-at-risk estimates of the stock indices in developed and emerging markets including the spillover effects of currency market." Economic Modelling 46: 204224.

http://dx.doi.org/10.1016/j.econmod.2014.12.022

Zaghini, A. and Colarossi, S. 2009. "Gradualism, transparency and the improved operational framework: a look at overnight volatility transmission." International Finance 12(2): 151-170. http://dx.doi.org/10.1111/j.1468-2362.2009.01241.x

Zhao, H. 2010. "Dynamic relationship between exchange rate and stock price: Evidence from China." Research in International Business and Finance 24(2): 103-112. http://dx.doi.org/10.1016/j.ribaf.2009.09.001

DOI: http://dx.doi.org/10.6000/1929-7092.2016.05.22

(C) 2016 Jung-Bin Su; Licensee Lifescience Global.

This is an open access article licensed under the terms of the Creative Commons Attribution Non-Commercial License (http://creativecommons.org/licenses/by-nc/3.0/) which permits unrestricted, non-commercial use, distribution and reproduction in any medium, provided the work is properly cited. 